\title{
Satellite-derived products of solar and longwave irradiances used for snowpack modelling in mountainous terrain
}

\author{
Louis Quéno $^{1,2, \text { : }}$, Fatima Karbou ${ }^{1}$, Vincent Vionnet ${ }^{1,3}$, and Ingrid Dombrowski-Etchevers ${ }^{4}$ \\ ${ }^{1}$ Univ. Grenoble Alpes, Université de Toulouse, Météo-France, CNRS, \\ CNRM, Centre d'Etudes de la Neige, 38000 Grenoble, France \\ ${ }^{2}$ WSL Institute for Snow and Avalanche Research SLF, Davos, Switzerland \\ ${ }^{3}$ Environmental Numerical Research Prediction, Environment and Climate Change Canada, Dorval, QC, Canada \\ ${ }^{4}$ CNRM, Université de Toulouse, Météo-France, CNRS, Toulouse, France \\ Invited contribution by Louis Quéno, recipient of the EGU Cryospheric Sciences Outstanding Student Poster and PICO \\ Award 2017.
}

Correspondence: Louis Quéno (louis.queno@gmail.com)

Received: 14 September 2017 - Discussion started: 19 September 2017

Revised: 13 March 2020 - Accepted: 25 March 2020 - Published: 28 April 2020

\begin{abstract}
In mountainous terrain, the snowpack is strongly affected by incoming shortwave and longwave radiation. In this study, a thorough evaluation of the solar and longwave downwelling irradiance products (DSSF and DSLF) derived from the Meteosat Second Generation satellite was undertaken in the French Alps and the Pyrenees. The satellitederived products were compared with forecast fields from the meteorological model AROME and with analysis fields from the SAFRAN system. A new satellite-derived product (DSLFnew) was developed by combining satellite observations and AROME forecasts. An evaluation against in situ measurements showed lower errors for DSSF than AROME and SAFRAN in terms of solar irradiances. For longwave irradiances, we were not able to select the best product due to contrasted results falling in the range of uncertainty of the sensors. Spatial comparisons of the different datasets over the Alpine and Pyrenean domains highlighted a better representation of the spatial variability of solar fluxes by DSSF and AROME than SAFRAN. We also showed that the altitudinal gradient of longwave irradiance is too strong for DSLFnew and too weak for SAFRAN. These datasets were then used as radiative forcing together with AROME near-surface forecasts to drive distributed snowpack simulations by the model Crocus in the French Alps and the Pyrenees. An evaluation against in situ snow depth measurements showed higher biases when using satellite-derived products, despite their quality. This effect is attributed to some error compensations in the atmospheric forcing and the snowpack model. However, satellite-derived irradiance products are judged beneficial for
\end{abstract}

snowpack modelling in mountains, when the error compensations are solved.

\section{Introduction}

Seasonal snowpacks are a key component of mountain hydrological systems. Snow accumulation and ablation processes set up the temporal evolution of the snow cover and its spatial distribution, controlling the snowmelt variability and timing, which govern the run-off in high-altitude catchments (e.g. Anderton et al., 2002; DeBeer and Pomeroy, 2017). The evolution and spatial distribution of the snowpack in mountainous terrain depends on its energy budget, affected by the surface radiative budget, the sensible and latent heat fluxes, and the ground heat flux (e.g. Armstrong and Brun, 2008). The meteorological conditions are the main factors controlling the snow surface energy budget, with a key contribution of the radiative components (Male and Granger, 1981). For example, Cline (1997) reported a contribution of $75 \%$ of net radiative fluxes in the energy for snowmelt over the entire season at a continental mid-latitude alpine site of the Colorado Front Range $(3517 \mathrm{~m})$, while Marks and Dozier (1992) found a contribution between $66 \%$ and $90 \%$ at two alpine sites of the Sierra Nevada (2800 and $3416 \mathrm{~m}$ ). Therefore, incoming shortwave (SW $\downarrow$ ) and longwave (LW $\downarrow$ ) radiative fluxes are amongst the most significant atmospheric factors of the energy and mass budget of the snowpack, particularly during snowmelt periods. It is crucial to accurately 
represent them in numerical snowpack simulations, as recent works underlined the strong sensitivity of snowpack simulations to the radiative forcing (Raleigh et al., 2015; Lapo et al., 2015b; Sauter and Obleitner, 2015), together with crucial input variables like precipitation and air temperature (Raleigh et al., 2015; Günther et al., 2019).

Several studies highlighted the benefits of distributed snowpack simulations at the scale of mountain ranges, particularly in areas with scarce snow cover observations. Simulations of detailed snowpack models driven by Numerical Weather Prediction (NWP) forecasts at kilometric resolution proved to describe satisfactorily the snowpack variability within a mountain range (Quéno et al., 2016; Vionnet et al., 2016), to describe the snow accumulation quantitative distribution (Schirmer and Jamieson, 2015) and to provide relevant high-resolution information for snowpack stability concerns (Bellaire et al., 2014; Horton et al., 2015). The radiative forcing of these simulations relies on NWP forecasts of the SW $\downarrow$ and LW $\downarrow$ irradiances with no use of observations (in situ or from satellites). Vionnet et al. (2016) made a preliminary evaluation of SW $\downarrow$ and $\mathrm{LW} \downarrow$ irradiance forecasts by the NWP system AROME operating at $2.5 \mathrm{~km}$ resolution over France. Through comparisons to ground-based measurements at two mountainous sites in the French Alps, they showed an overestimation of SW $\downarrow$ and an underestimation of LW $\downarrow$, linked to an underestimation of the cloud cover.

Satellite-derived estimates of SW $\downarrow$ and LW $\downarrow$ irradiances are an alternative to NWP-based irradiance datasets in mountainous terrain. They are mostly based on satellite products of cloud mask, which highly controls the incoming radiation in mountains (e.g. Sicart et al., 2016), and top-of-atmosphere reflectances. These satellite-based products could have a potential added value for snowpack modelling since they are available continuously and at a relatively high resolution in mountains, where in situ observations are rather scarce. This approach has already been explored with the solar and longwave surface irradiance data from NASA's Clouds and the Earth's Radiant Energy System synoptic (CERES SYN; Rutan et al., 2015), which are satellite-derived estimates at $3 \mathrm{~h}$ temporal resolution and $1^{\circ}$ grid spacing (i.e. approximately $110 \mathrm{~km}$ at mid-latitudes). The quality of CERES SYN irradiances was found to be poorer at mountain stations than those on plains (Hinkelman et al., 2015). The CERES SYN solar irradiance product was also evaluated by Lapo et al. (2017), who found large biases over complex terrain. Hinkelman et al. (2015) used CERES SYN irradiance products to drive snowmelt simulations in complex terrain and found performances in the range of empirical methods and observations. In this study, we used the SW $\downarrow$ and $\mathrm{LW} \downarrow$ irradiances from the Satellite Application Facility on Land Surface Analysis (LSA SAF; Trigo et al., 2011), derived from Meteosat Second Generation (MSG) satellite data. These products have a higher temporal frequency (30 $\mathrm{min})$ and a higher spatial resolution ( $3 \mathrm{~km}$ at nadir) and thus may be more adapted than CERES SYN products to complex terrains, where the sub- grid variability of incoming radiation within a $1^{\circ}$ grid cell is the highest (Hakuba et al., 2013). In a perspective of distributed snowpack simulations at kilometric resolution, they are also consistent with the horizontal resolution of the other atmospheric variables from NWP systems. LSA SAF irradiance products were proved to be valuable for plains (e.g. Geiger et al., 2008b; Ineichen et al., 2009; Trigo et al., 2010; Carrer et al., 2012; Moreno et al., 2013; Cristóbal and Anderson, 2013), with a significant positive impact when used for simulations of the surface and soil temperatures, and soil water content (Carrer et al., 2012) or evapotranspiration modelling (Ghilain et al., 2011; Sun et al., 2011). MSG satellite data have already been used to derive incoming solar irradiance over complex terrain in the Heliomont method (Stöckli, 2013; Castelli et al., 2014), but at a much finer scale (100 m) than the scope of this study.

The aim of the present study is to assess LSA SAF products of SW $\downarrow$ and LW $\downarrow$ irradiances in the French Alps and the Pyrenees, and to compare them with kilometric-resolution NWP forecasts and with a meteorological analysis system dedicated to mountainous terrain. We also test and discuss the potential of LSA SAF irradiance products to drive distributed snowpack simulations in mountains. With regard to the existing literature on the subject, this article makes three original contributions: (i) in-depth evaluation of LSA SAF irradiance products in mountains, (ii) development and assessment of a new LW $\downarrow$ irradiance product to better capture the spatial variability of LW $\downarrow$ irradiance in complex terrain, and (iii) use of satellite-derived irradiance products at higher spatial and temporal resolution than previous studies to drive distributed snowpack simulations over large mountain areas.

\section{Data and models}

\subsection{Study domain and period}

The study focuses on two domains covering the French Alps (Fig. 1a) and the French and Spanish Pyrenees (Fig. 1b). The French Alps domain ranges from 43.125 to $46.875^{\circ} \mathrm{N}$ latitudes and from 4.5 to $8.5^{\circ} \mathrm{E}$ longitudes. This domain also includes a part of the mid-altitude mountain range of Jura. The Pyrenees domain covers the latitudes from 41.6 to $43.6^{\circ} \mathrm{N}$ and the longitudes from -2.5 to $3.5^{\circ} \mathrm{E}$. Hourly data, from 1 August 2010 to 31 July 2014, including in situ measurements, satellite-derived irradiance products, meteorological models and snowpack simulations, were used.

\subsection{Irradiance datasets}

Several irradiance datasets were used in this study: forecasts from the NWP model AROME, reanalyses from the SAFRAN analysis system, LSA SAF irradiance products derived from remotely sensed observations and a hybrid LW $\downarrow$ irradiance product based on a combination of LSA SAF algo- 

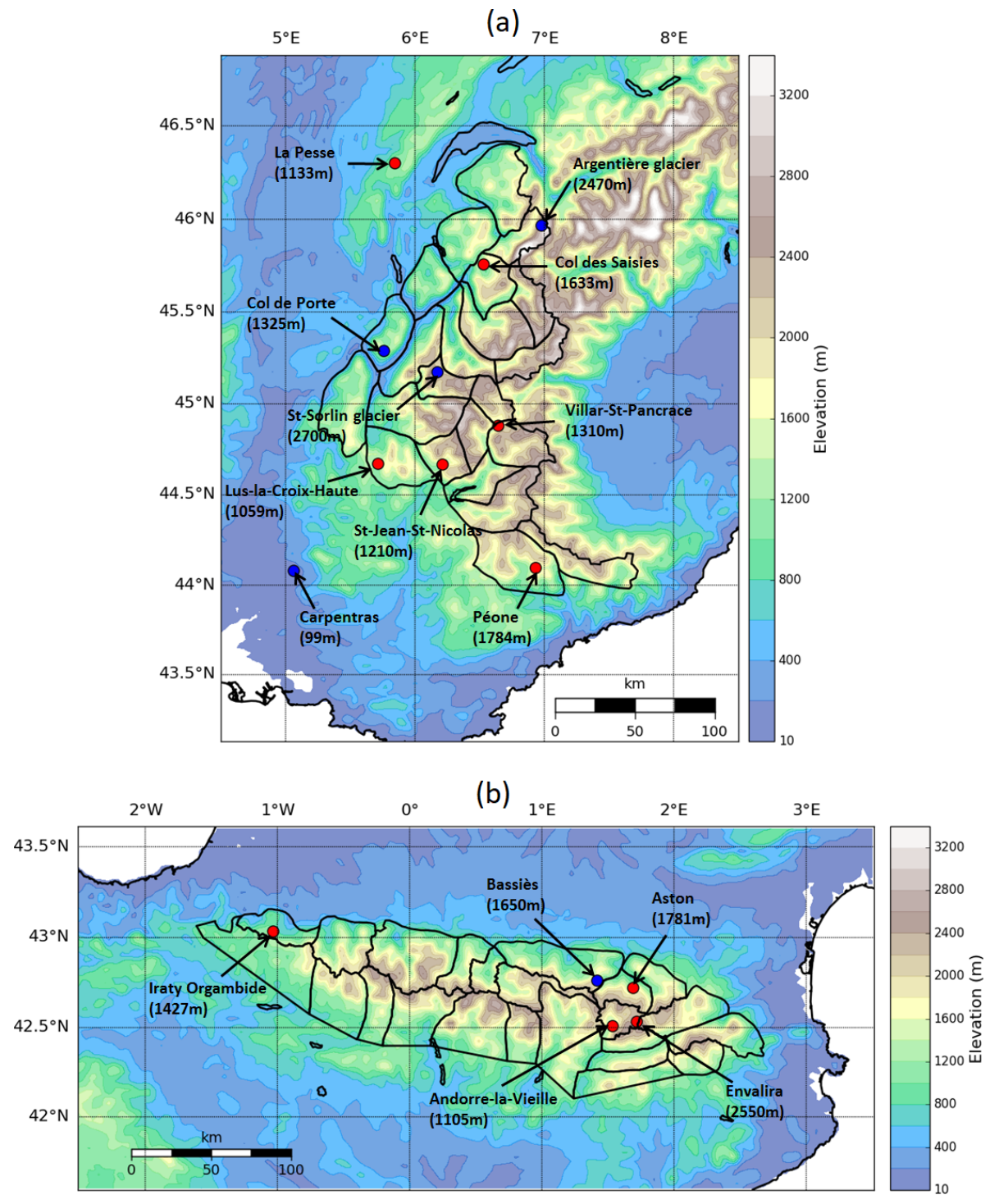

Figure 1. Domains of study: (a) the French Alps and (b) the Pyrenees, with AROME topography at $2.5 \mathrm{~km}$ resolution. Red dots: SW $\downarrow$ stations; blue dots: $\mathrm{SW} \downarrow$ and $\mathrm{LW} \downarrow$ stations; black lines: SAFRAN massifs.

rithms with AROME forecasts. An in situ observation dataset was built up for validation in mountains.

\subsubsection{NWP system: AROME}

AROME (Application of Research to Operations at MEsoscale) is the meso-scale NWP system of MétéoFrance (Seity et al., 2011), operating over France since December 2008 at $2.5 \mathrm{~km}$ grid spacing $(1.3 \mathrm{~km}$ since 2015 ; Brousseau et al., 2016). It is a spectral and non-hydrostatic model. The physics and data assimilation schemes are detailed in Seity et al. (2011). In particular, AROME uses the radiation parameterizations from the European Centre for Medium-Range Weather Forecasts (ECMWF), with the SW scheme from Fouquart and Bonnel (1980) and the LW scheme from Mlawer et al. (1997).

In this study, we built a continuous atmospheric forcing dataset to drive snowpack simulations using hourly AROME forecasts issued from the 00:00 UTC analysis time, from +6 to $+29 \mathrm{~h}$, extracted on a regular latitude-longitude grid with a $0.025^{\circ}$ resolution over the period and domains of the study (Sect. 2.1, Fig. 1), similarly to Quéno et al. (2016) and Vionnet et al. (2016). Besides incoming shortwave and longwave irradiances, $2 \mathrm{~m}$ temperature and humidity as well as $10 \mathrm{~m}$ wind speed and ground-level precipitation (amount of rainfall and snowfall) are part of the AROME forcing. The variable heights correspond to the heights of the diagnostic variables provided by AROME. 


\subsubsection{Analysis system: SAFRAN}

SAFRAN (Système d'Analyse Fournissant des Renseignements Atmosphériquesà la Neige; Analysis System Providing Atmospheric Information to Snow; Durand et al., 1993, 2009a, b) is a meteorological analysis system developed to provide hourly estimation of meteorological parameters required to drive land surface models. SAFRAN outputs are available per $300 \mathrm{~m}$ altitude steps within mountainous regions called "massifs". There are 23 massifs in the French Alps and 23 massifs in the French and Spanish Pyrenees (Fig. 1), defined for their climatological homogeneity. SAFRAN reanalyses take a preliminary guess from the global NWP model ARPEGE (from Météo-France, $15 \mathrm{~km}$ grid spacing projected on a $40 \mathrm{~km}$ grid; Courtier et al., 1991) combined by optimal interpolation with available observations from automatic weather stations, manual observations carried out in the climatological network and in ski resorts, remotely sensed cloudiness and atmospheric upperlevel soundings. In particular, the incoming shortwave and longwave fluxes are computed with the radiation scheme from Ritter and Geleyn (1992), using as first guess vertical profiles of temperature and humidity from ARPEGE forecasts, atmospheric soundings; a guess of cloudiness based on the analysed vertical humidity profile; and a cloud mask detected by satellite (Derrien et al., 1993).

In this study, we used SAFRAN reanalyses from $1 \mathrm{Au}-$ gust 2010 to 31 July 2014. For comparisons to in situ irradiance observations, the reanalyses were interpolated at the exact elevation of the stations, through a weighted mean of SAFRAN reanalyses at the two closest elevation levels in the massif considered. For La Pesse station in Jura (Fig. 1a), the extension of SAFRAN to mid-altitude French massifs (Lafaysse et al., 2013) was used. For Carpentras station, on a plain (Fig. 1a), the SAFRAN-France extension (QuintanaSeguí et al., 2008) was considered. For distributed comparisons and for the atmospheric forcing of distributed snowpack simulations, the reanalyses at massif-scale in the French Alps and in the Pyrenees were interpolated over the $0.025^{\circ}$ grid of the AROME forcing, within SAFRAN massifs, similarly to Quéno et al. (2016) and Vionnet et al. (2016), following the method described in Vionnet et al. (2012).

\subsubsection{LSA SAF products}

The LSA SAF is a project supported by the European Organisation for the Exploitation of Meteorological Satellites (EUMETSAT) and a consortium of European National Meteorological Services, with the purpose of using remotely sensed data to determine land surface variables (Trigo et al., 2011). In particular, it provides estimates of the downward surface shortwave flux (DSSF) and the downward surface longwave flux (DSLF), derived from the Spinning Enhanced Visible and Infrared Imager (SEVIRI) radiometer on board the MSG geostationary satellite (Schmetz et al., 2002). They are gen- erated every $30 \mathrm{~min}$, covering the MSG full disc with a $3 \mathrm{~km}$ resolution at nadir. They have been operationally disseminated since September 2005 (http://landsaf.ipma.pt, last access: 20 April 2020). DSSF and DSLF are fully consistent as they are based on the same satellite observations.

- SW $\downarrow$ irradiance: DSSF

The algorithm to estimate the DSSF is described in detail by Geiger et al. (2008b). The MSG/SEVIRI cloud mask (Derrien and Le Gléau, 2005) identifies clearsky and cloudy-sky situations. Two separate algorithms are then applied. In the clear-sky method, derived from Frouin et al. (1989), the effective transmittance of the atmosphere is parameterized using the total column water vapour content (TCWV) forecast by the European Centre for Medium-Range Weather Forecasts (ECMWF) Integrated Forecasting System (IFS), the ozone amount from the Total Ozone Mapping Spectrometer climatology, a constant visibility and the surface albedo taken from the LSA SAF albedo product (Geiger et al., 2008a). In the cloudy-sky method, derived from Gautier et al. (1980) and Brisson et al. (1999), the topof-atmosphere reflectance observed by MSG/SEVIRI is used in addition to the former set of variables to apply a simple physical model of radiative transfer. Contrary to the Heliomont solar irradiance product also derived from MSG data (Stöckli, 2013; Castelli et al., 2014), the DSSF is not down-scaled over complex terrain, and thus not corrected for local topography effects. The target accuracy of the DSSF is $10 \%$ or $20 \mathrm{~W} \mathrm{~m}^{-2}$ for values lower than $200 \mathrm{~W} \mathrm{~m}^{-2}$ (Trigo and Viterbo, 2009).

- LW $\downarrow$ irradiance: DSLF

The algorithm to estimate the DSLF is described in detail by Trigo et al. (2010). It consists of a modified version of the bulk parameterization of Prata (1996), initially developed for clear skies only. It relies on a formulation of the effective emissivity and temperature of the atmospheric layer above the surface, using the TCWV, $2 \mathrm{~m}$ temperature $\left(T_{2 \mathrm{~m}}\right)$ and $2 \mathrm{~m}$ dew point $\left(\mathrm{Td}_{2 \mathrm{~m}}\right)$ forecast by the ECMWF IFS. The formulation parameters are calibrated for clear-sky and overcast conditions independently. The MSG/SEVIRI cloud mask (Derrien and Le Gléau, 2005) is thus the only observation used, to distinguish clear-sky and cloudy-sky situations. In the case of partly cloudy situations, the average of both terms is taken. The DSLF can therefore be described more accurately as a longwave irradiance parameterization using satellite observations of the cloud mask rather than a satellite product. The DSLF is not down-scaled over complex terrain, and thus not corrected for local topography effects. The target accuracy of the DSLF is $10 \%$ (Trigo and Viterbo, 2009). 


\subsubsection{New DSLF product using AROME forecasts}

The DSLF relies on the ECMWF IFS forecasts of TCWV, $T_{2 \mathrm{~m}}$ and $\mathrm{Td}_{2 \mathrm{~m}}$. These atmospheric variables have a strong dependence on altitude and a strong spatial variability in mountainous terrain. The $16 \mathrm{~km}$ horizontal resolution of the ECMWF IFS hardly represents this spatial variability in the Alps and the Pyrenees, despite a constant lapse rate applied for grid elevation correction. Consequently, we developed a new DSLF product using the same algorithm (Trigo et al., 2010) depending on the cloud mask (Derrien and Le Gléau, 2005), but replacing ECMWF forecasts with AROME forecasts at $2.5 \mathrm{~km}$ resolution, which provides a finer representation of the topography. Air temperature and dew point were taken at $20 \mathrm{~m}$ above the ground in the archive of the AROME operational forecast. This height corresponds approximately to the height of the first prognostic level in the operation version of AROME over the period 2010-2014 (Seity et al., 2011). The use of AROME also implies a better agreement of the atmospheric forecast resolution $(2.5 \mathrm{~km})$ with the cloud mask and final product resolution $(3 \mathrm{~km})$.

The new product was generated on the exact same grid as DSLF, in order to enable direct comparisons, so AROME forecasts were interpolated over the LSA SAF grid through a closest-neighbour method (similar grid spacing). The possible altitude difference between AROME grid points and LSA SAF grid points was mitigated thanks to a vertical temperature gradient of $-6.5 \mathrm{~K} \mathrm{~km}^{-1}$ according to the International Standard Atmosphere, similarly to the method applied to ECMWF IFS forecasts. The algorithm was applied to the new DSLF on the LSA SAF grid over the domains of study (Fig. 1), from 1 August 2010 to 31 July 2014. Hereafter, this product is referred to as DSLFnew.

\subsubsection{In situ irradiance observations}

To assess the distributed irradiance datasets, ground measurements of SW $\downarrow$ and $\mathrm{LW} \downarrow$ were extracted from the MétéoFrance station network and additional automatic weather stations (AWSs). Stations with altitude higher than $1000 \mathrm{~m}$ were selected. As elevation influences incoming radiation (Oliphant et al., 2003), stations were not used for evaluation if the difference between the station elevation and the elevation of the four closest AROME and LSA SAF grid points was higher than $300 \mathrm{~m}$. As elevation differences up to $300 \mathrm{~m}$ may have an influence on the comparisons, the altitudes of the grid points associated with each station are listed in Table 1 and should be kept in mind when analysing the evaluation statistics. The resulting observation database, represented in Fig. 1, includes 14 mountain SW $\downarrow$ stations (8 in the French Alps, 1 in Jura and 5 in the Pyrenees) and 4 mountain LW $\downarrow$ stations (3 in the French Alps and 1 in the Pyrenees). An additional station located on a plain at Carpentras (Fig. 1) has been included in the database since it is the ref- erence station for SW $\downarrow$ and $\mathrm{LW} \downarrow$ measurements in France. These stations and their characteristics are listed in Table 1.

Irradiance measurements are scarce in mountainous terrain and their quality is often lower than plain measurements, due to the difficulty of maintaining these stations and the possible occurrence of frost or snow on the sensors in winter (Lapo et al., 2015a). The pyranometers from MétéoFrance network (Kipp\&Zonen CM5, CM6B and CM11) meet the quality standards of the World Meteorological Organization (WMO, 2014) and hence an uncertainty of hourly total SW $\downarrow$ irradiance of $\pm 10 \%$ (Leroy and Leches, 2014). Due to their altitude, the maintenance may not be systematically weekly so that uncertainties of $\pm 10 \%$ are probably too optimistic. The station of Carpentras, on a plain, is equipped with the pyranometer Kipp \& Zonen CM21 and the pyrgeometer Kipp \& Zonen CG4. This station is a reference station for radiation measurements, as it is part of the Baseline Surface Radiation Network (BSRN; Ohmura et al., 1998): the uncertainties are $\pm 3 \%$ for $\mathrm{SW} \downarrow$ and $\pm 5 \%$ for $\mathrm{LW} \downarrow$. At Col de Porte where the pyranometer Kipp \& Zonen CM14 and the pyrgeometer Kipp \& Zonen CG4 undergo regular maintenance, Morin et al. (2012) reported total uncertainty on the order of $\pm 10 \%$ (including site-dependent uncertainties). The AWSs of Bassiès (Szczypta et al., 2015), Argentière glacier and Saint-Sorlin glacier (data from GLACIOCLIM program, https://glacioclim.osug.fr, last access: 20 April 2020) have Kipp \& Zonen CM3 pyranometers and CG3 pyrgeometers, classified as moderate quality after WMO's standards (WMO, 2014), for which the manufacturer reports a daily total accuracy of $\pm 10 \%$. The uncertainties have not been estimated at these stations. They are possibly higher than $10 \%$ because of the difficulty of maintaining AWSs in complex environments, particularly in winter. WMO (2014) indicates uncertainties up to $\pm 20 \%$ for hourly totals for this kind of instruments. The results at these stations are indicative for high altitudes but shall be considered carefully. Table 1 summarizes the measurement uncertainties at each station.

$\mathrm{SW} \downarrow$ and LW $\downarrow$ irradiances from LSA SAF products, AROME forecasts and SAFRAN reanalyses were evaluated using these in situ measurements. The altitude of the grid points associated with each station is reported in Table 1. Biases and root mean square errors (RMSEs) were computed in absolute and relative values (with the mean of observations as reference). To account for topographic shading on irradiance in situ measurements, a topographic mask was computed with a $5^{\circ}$ interval size after a $25 \mathrm{~m}$ resolution digital elevation model (DEM) of IGN (French National Institute of Geographical and Forest Information) and applied to the $\mathrm{SW} \downarrow$ irradiance products at all stations except Andorre and Envalira, because the DEM of IGN was only available on the French territory. The $S W \downarrow$ irradiance products were only evaluated when the sun was above the horizon, or when the observed value was higher than $20 \mathrm{~W} \mathrm{~m}^{-2}$ at Andorre and Envalira stations (to discard periods when the sun is masked 


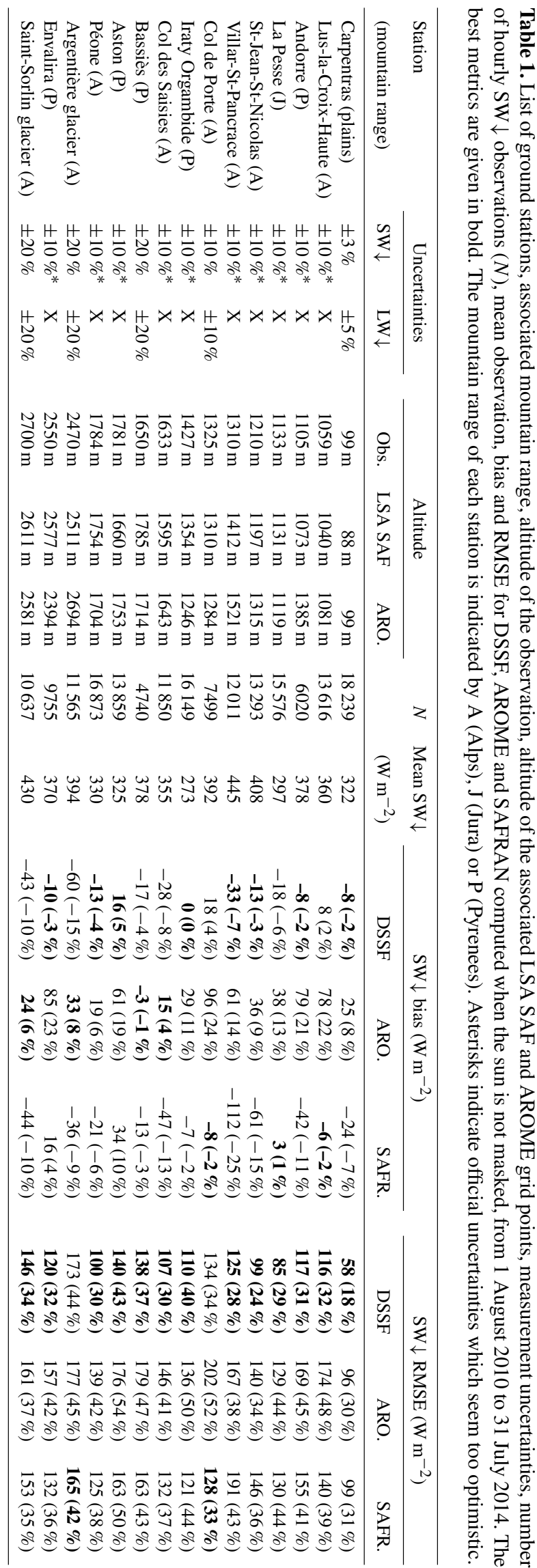

by the terrain). The $\mathrm{LW} \downarrow$ irradiance products were evaluated by day and night.

\subsection{Snowpack datasets}

The impact of the different irradiance datasets on distributed snowpack simulations is assessed using the snowpack model Crocus with different atmospheric forcings. These simulations are compared to in situ measurements of snow depth.

\subsubsection{Snowpack model: Crocus}

Snowpack simulations driven by different irradiance datasets were performed with the detailed snow cover model Crocus (Brun et al., 1992; Vionnet et al., 2012) coupled with the ISBA land surface model within the SURFEX simulation platform (Masson et al., 2013), to fully simulate the interactions between snowpack and soil. SURFEX/ISBA-Crocus (called Crocus hereafter) simulates the evolution of the snowpack physical properties along its stratigraphy, under given atmospheric forcing data (temperature and specific humidity at a given height above the surface, wind speed at a given height above the surface, $\mathrm{SW} \downarrow$ and LW $\downarrow$ irradiance, solid and liquid precipitation).

The simulations were carried out over the French Alps and Pyrenees domains (Fig. 1), on the AROME regular latitudelongitude grid at $0.025^{\circ}$ resolution (Sect. 2.2.1) from $1 \mathrm{Au}-$ gust 2010 to 31 July 2014. The effects of aspect and slope on incoming solar irradiance were not taken into account, because the snowpack is simulated over flat terrain, and the interactions with the vegetation and the parameterization of fractional snow cover were not activated, because the evaluation observations are located in flat and open fields. This configuration has already been used in Vionnet et al. (2016) and Quéno et al. (2016).

Except for incoming radiative fluxes, the atmospheric forcing of the snowpack simulations was built with AROME forecasts (Sect. 2.2.1). The radiative components of the forcings were extracted from the different irradiance datasets: (a) AROME irradiance forecasts (simulations named A-Cro hereafter), (b) SAFRAN irradiance reanalyses (simulations named AS-Cro hereafter), (c) DSSF and DSLFnew (simulations named AL-Cro hereafter), (d) DSSF and AROME $\mathrm{LW} \downarrow$ irradiance (simulations named $\mathrm{AL}_{\mathrm{SW}}$-Cro hereafter), and (e) DSLFnew and AROME SW $\downarrow$ irradiance (simulations named $\mathrm{AL}_{\mathrm{LW}}$-Cro hereafter). In order to include DSSF and DSLFnew products in AROME forcing, the interpolation on the AROME grid was made to minimize the effect of elevation difference on the incoming radiative fluxes. Among the four nearest LSA SAF grid points, the grid point with the minimum altitude difference with AROME grid point was chosen. Similarly to Hinkelman et al. (2015), SW $\downarrow$ irradiances were not modified, whereas a vertical gradient of $-29 \mathrm{~W} \mathrm{~m}^{-2} \mathrm{~km}^{-1}$ (Marty et al., 2002) was applied to LW $\downarrow$ 
(a)

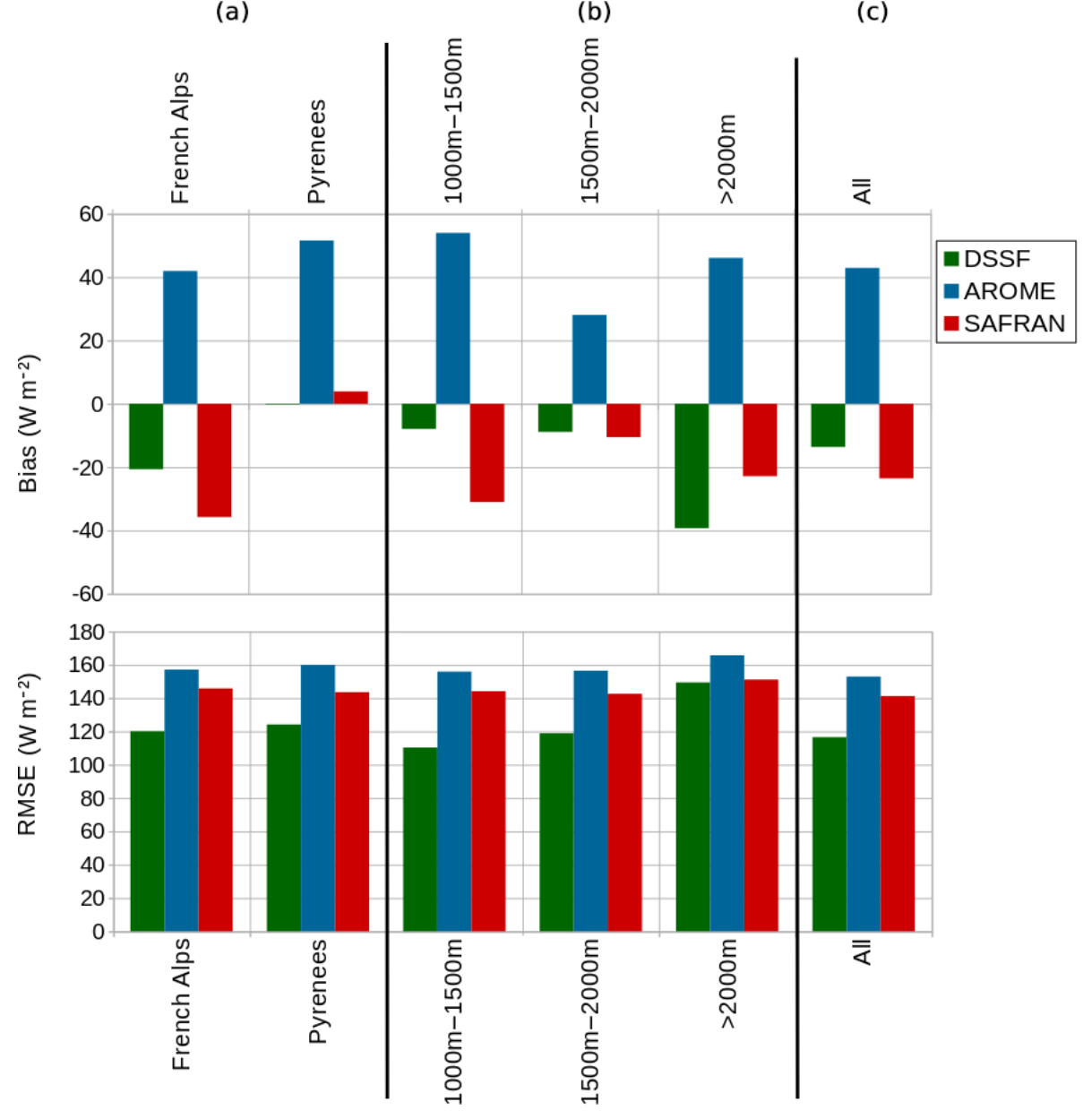

Figure 2. Bias and RMSE of SW $\downarrow$ irradiance products (DSSF in green, AROME in blue, SAFRAN in red) compared to stations organized by domain (a), range of altitude (b) and all stations (c).

irradiances to mitigate the remaining differences in altitude. The different simulations are summarized in Table 2.

\subsubsection{In situ snowpack observations}

To assess the quality of Crocus simulations, an observational dataset of snow depth measurements was constituted in the French Alps and the Pyrenees, within SAFRAN massifs. Only stations with less than $150 \mathrm{~m}$ elevation difference to the model topography were selected, in order to use the same dataset as Quéno et al. (2016) and Vionnet et al. (2016). This dataset contains a total of 172 stations (89 in the French Alps and 83 in the Pyrenees) with daily manual measurements at ski resorts (at 06:00 UTC) and daily automatic measurements by ultra-sonic sensors at high-altitude sensors, as described in detail in Vionnet et al. (2016) for the French Alps and in Quéno et al. (2016) for the French and Spanish Pyrenees.

\section{Evaluation of irradiance products over the Alps and the Pyrenees}

\subsection{Comparisons with in situ measurements}

The SW $\downarrow$ error statistics for all stations are listed in Table 1. For most stations, DSSF shows the lowest biases with an underestimation of $S W \downarrow$. Biases are also mostly negative for SAFRAN, while AROME exhibits strong positive biases at most of the stations. DSSF exhibits the lowest RMSE at almost all stations. For all products, the lowest RMSE is reached at Carpentras on the plain. These metrics are summarized in Fig. 2. The distinction by domain (French Alps and Pyrenees) shows that the three products have very similar RMSE over both domains, which highlights the consistency of these error statistics. The distinction by range of altitude (1000-1500, 1500-2000, > $2000 \mathrm{~m}$ ) shows increasing RMSE with altitude for DSSF, while RMSE are higher but more constant for AROME and SAFRAN. The increasing RMSE of DSSF is mainly due to stronger negative biases at 
Table 2. Characteristics of the snowpack simulations.

\begin{tabular}{llllll}
\hline Simulation names & A-Cro & AS-Cro & AL-Cro & AL $_{S W}$-Cro & AL $L$-Cro \\
\hline Atmospheric forcing (except irradiance) & & & AROME & & \\
SW $\downarrow$ forcing & AROME & SAFRAN & DSSF & DSSF & AROME \\
LW forcing & AROME & SAFRAN & DSLFnew & AROME & DSLFnew \\
\hline
\end{tabular}

(a)

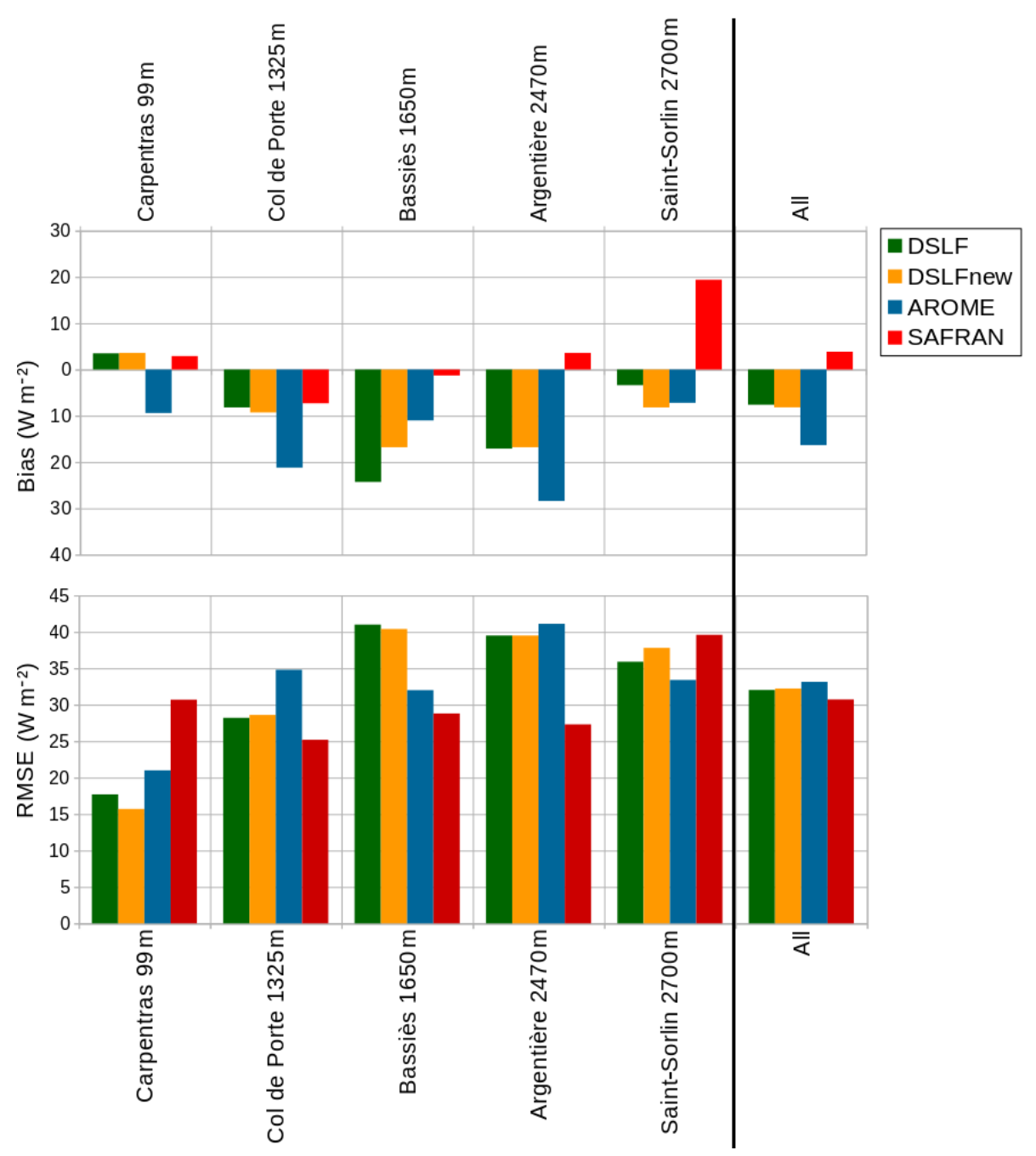

Figure 3. Bias and RMSE of LW $\downarrow$ irradiance products (DSLF in green, DSLFnew in orange, AROME in blue, SAFRAN in red) compared to each station (a) and all stations (b).

high altitudes $\left(-39 \mathrm{~W} \mathrm{~m}^{-2}\right.$ above $2000 \mathrm{~m}$ against $-8 \mathrm{~W} \mathrm{~m}^{-2}$ between 1000 and $1500 \mathrm{~m}$ ). SAFRAN biases are negative at all altitudes while AROME biases are positive at all altitudes. Overall, DSSF exhibits the best performance with a relative bias of $-4 \%$ and a relative RMSE of $33 \%$. SAFRAN has a relative bias of $-7 \%$ and a relative RMSE of $40 \%$. Finally, AROME exhibits the strongest relative bias $(+12 \%)$ and the highest relative RMSE (43\%).
Figure 3 shows the biases and RMSEs of the different datasets of incoming LW $\downarrow$ (DSLF, DSLFnew, AROME and SAFRAN) at the five LW $\downarrow$ stations and the overall error statistics. In this figure, stations are ordered by altitude. In mountains, DSLF, DSLFnew and AROME have a negative bias, while SAFRAN bias tends to increase with altitude. At low elevation (Carpentras), the best performance is in favour of DSLFnew with a bias of $+4 \mathrm{~W} \mathrm{~m}^{-2}(+1 \%)$ and a RMSE of $16 \mathrm{~W} \mathrm{~m}^{-2}(5 \%)$, which falls within the range of uncer- 

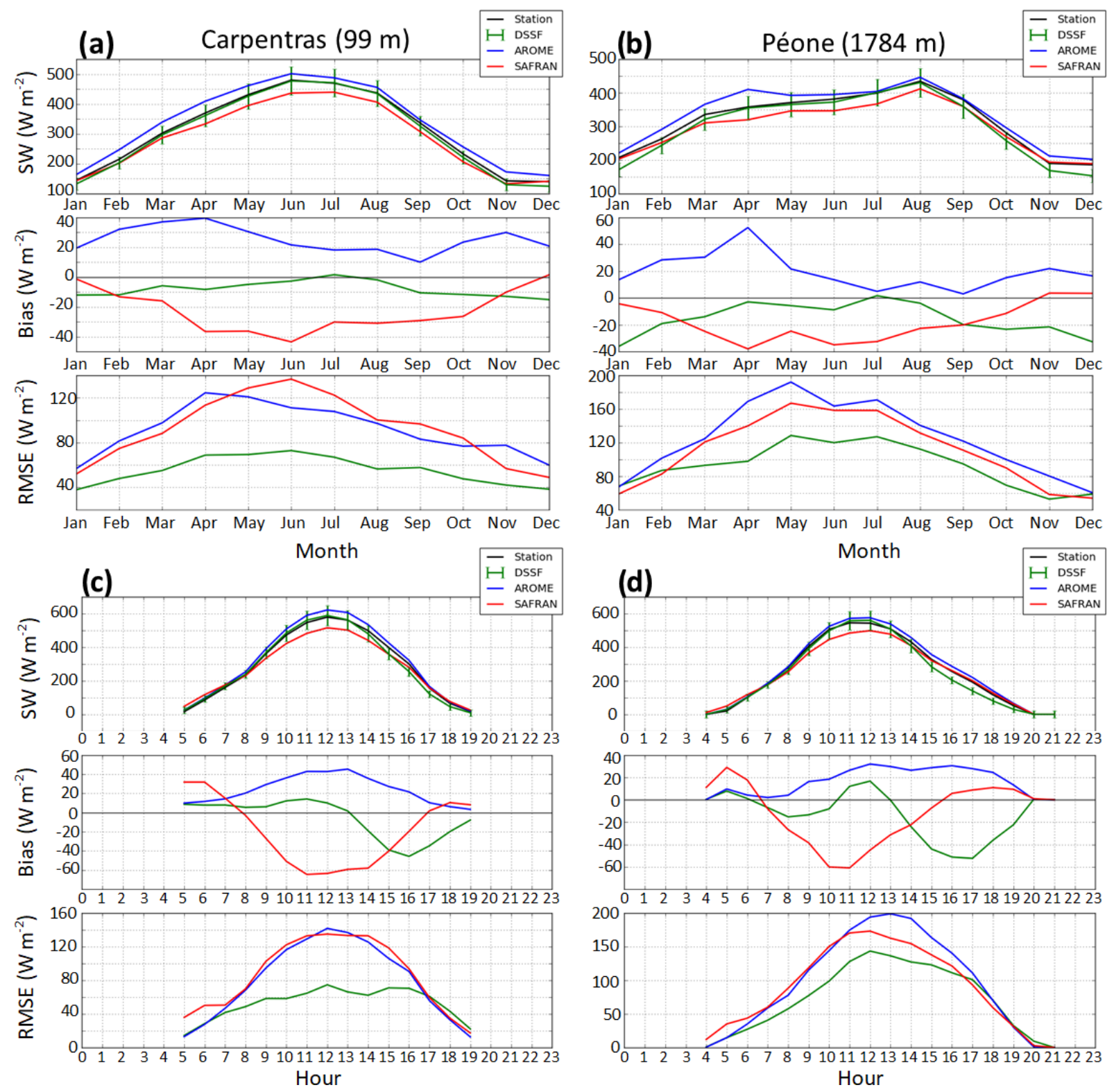

Figure 4. Mean yearly cycles of SW $\downarrow$ irradiance products (DSSF in green, AROME in blue, SAFRAN in red), ground measurements (in black), bias and RMSE over the 2010-2014 period at (a) Carpentras and (b) Péone. Mean daily cycles of the same products, bias and RMSE over the 2010-2014 period at (c) Carpentras and (d) Péone.

tainties of the sensor. At three mountain stations ( $\mathrm{Col}$ de Porte, Bassiès and Argentière glacier), the lowest bias and RMSE are reached by SAFRAN, while AROME has the lowest RMSE at the Saint-Sorlin glacier. Overall, AROME exhibits the strongest negative relative bias $(-6 \%)$ and the highest relative RMSE (12\%). DSLF and DSLFnew have equivalent error statistics with a relative bias of $-3 \%$ and a relative RMSE of $11 \%$. Finally, SAFRAN has a relative bias of $+1 \%$ and a relative RMSE of $11 \%$. These global error statistics are close to the sensor uncertainties in mountains, which does not enable "best product" to be chosen. However, some trends are identified, such as an underesti- mation of LW $\downarrow$ by DSLF, DSLFnew and AROME. The performance of LSA SAF products and models is also clearly better in terms of LW $\downarrow$ than $\mathrm{SW} \downarrow$, because of lower biases and RMSE.

The yearly cycles of $\mathrm{SW} \downarrow$ irradiances are illustrated at Carpentras for reference (Fig. 4a) and at Péone mountain station (Fig. 4b). They show higher RMSE in spring and summer for each dataset, the lowest RMSE for DSSF and the highest RMSE for AROME during the whole year, except in December and January when the three products have equivalent RMSEs. This trend was found to be similar at all stations. No specific trend was observed for the bias. The $\mathrm{SW} \downarrow$ 

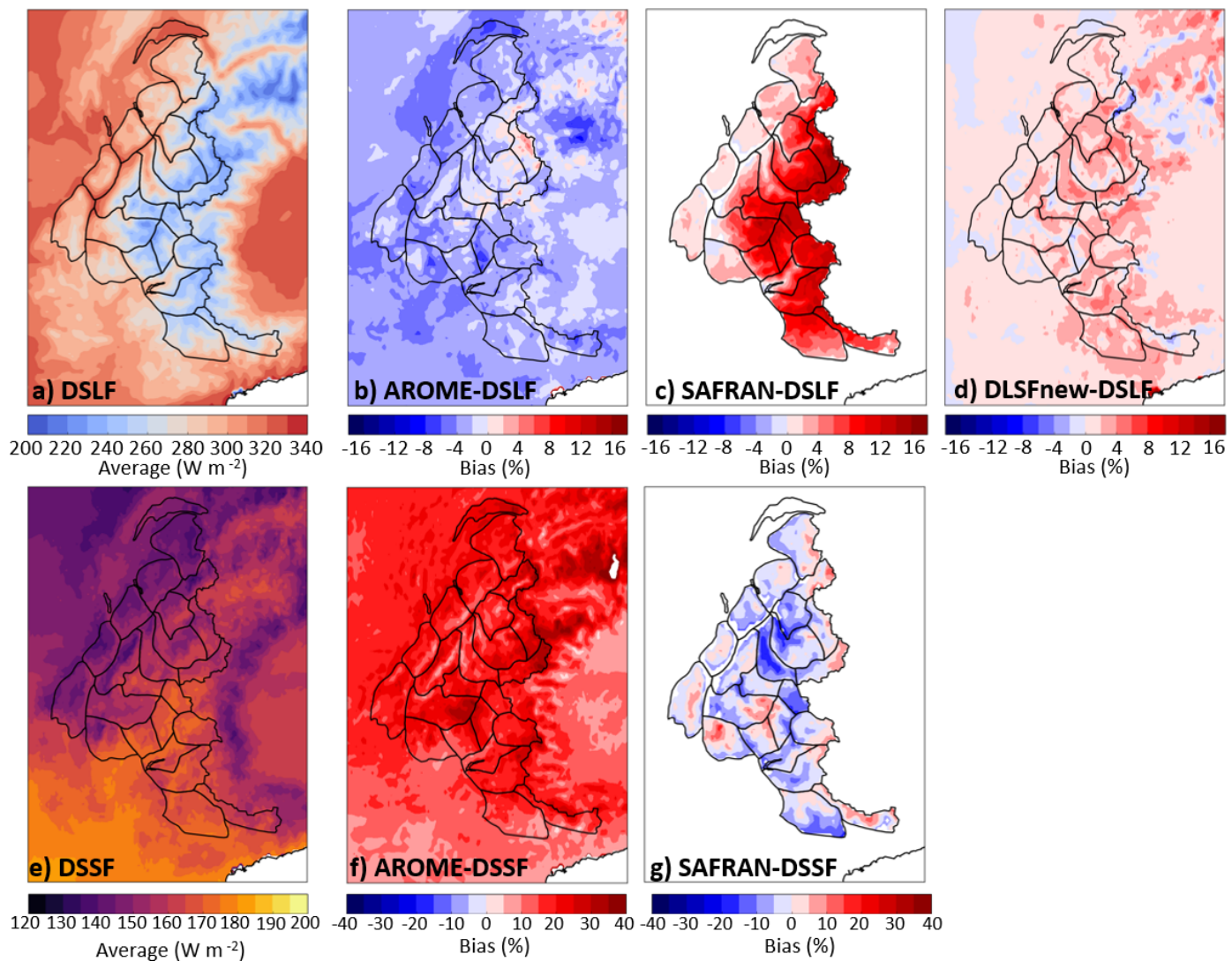

Figure 5. (a) Average of the DSLF from 1 August 2010 to 31 July 2014 in the French Alps, and relative difference with the DSLF for (b) AROME, (c) SAFRAN and (d) DSLFnew. (e) Average of the DSSF, and relative difference with the DSSF for (f) AROME and(g) SAFRAN.

daily cycles (Fig. 4c for Carpentras and Fig. 4d for Péone) show a lower RMSE for DSSF in the middle of the day. The SAFRAN cycle is not marked enough (positive biases in the morning and evening, negative biases in the middle of the day). AROME overestimates $S W \downarrow$ all the time. DSSF represents the diurnal cycle well, with an underestimation in the afternoon. These trends were also highlighted at the other mountain stations. The study of the daily and yearly cycles of $\mathrm{LW} \downarrow$ irradiances did not indicate any particular trend for metrics following the month or the hour (not shown).

\subsection{Spatial comparisons of the distributed products}

Spatial comparisons of the different irradiance products were carried out over the two domains. DSSF and DSLF were taken as references. The spatial distributions of their annual mean computed using data from 1 August 2010 to 31 July 2014 and the differences with the other irradiance products are shown in Fig. 5 for the French Alps and in Fig. 6 for the Pyrenees.

The DSLF exhibits a strong correlation with the altitude, with a decreasing LW irradiance towards the highest elevations, i.e. the east of the French Alps (Fig. 5a) and the central range of the Pyrenees (Fig. 6a). AROME presents a moderate negative bias as compared to the DSLF, both in the Alps (Fig. 5b) and in the Pyrenees (Fig. 6b), while SAFRAN presents a strong positive bias, particularly in the highest areas of the Alps (Fig. 5c) and the Pyrenees (Fig. 6c). DLSFnew presents a slight positive bias over most of the domains, except over the highest peaks where the bias is slightly negative (Figs. 5d and 6d).

The DSSF exhibits a lower correlation with the topography (Figs. 5e and 6e). For given sky conditions, the SW irradiance increases with the elevation as the atmospheric transmissivity increases. But the annual mean of the DSSF follows more regional patterns of cloud cover than elevation patterns. For example, in the French Alps, Fig. 5e shows a north-west-south-east gradient of increasing DSSF: southeastern massifs are often shielded by north-western massifs in the most frequent case of west and north-west disturbed flows. A similar gradient of precipitation was shown in $\mathrm{Du}-$ rand et al. (2009b). The heterogeneity of DSSF is even more marked in the Pyrenees (Fig. 6e) where the west-east chain acts as an orographic barrier to the prevailing northwesterlies coming from the Atlantic Ocean (Quéno et al., 2016). A clear discontinuity appears between the French Pyrenees, 

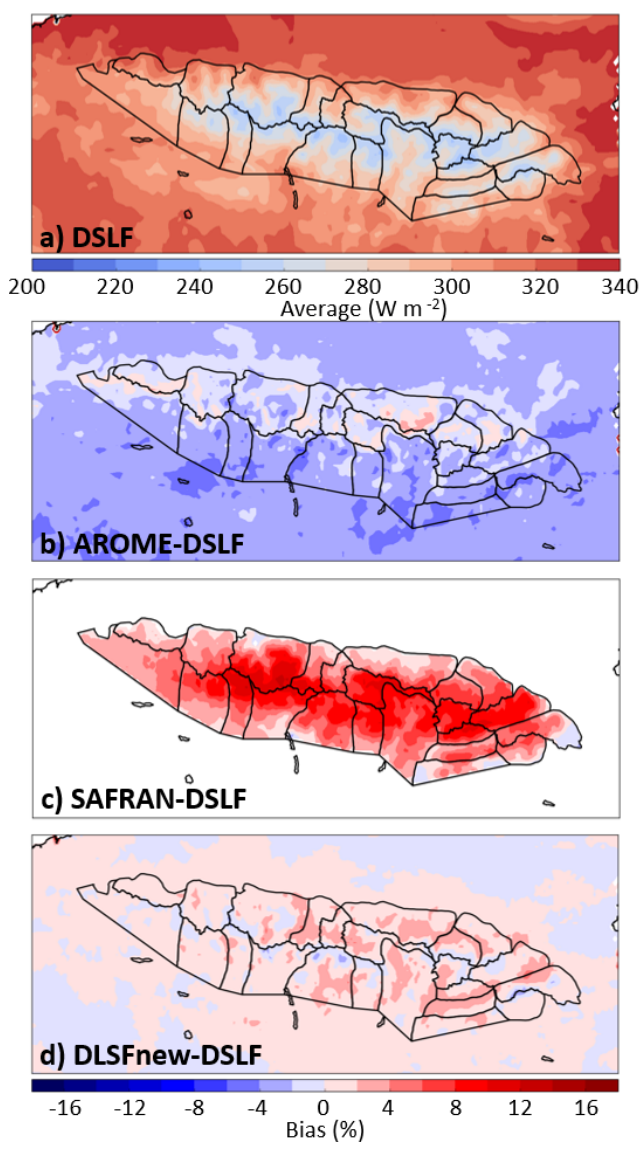
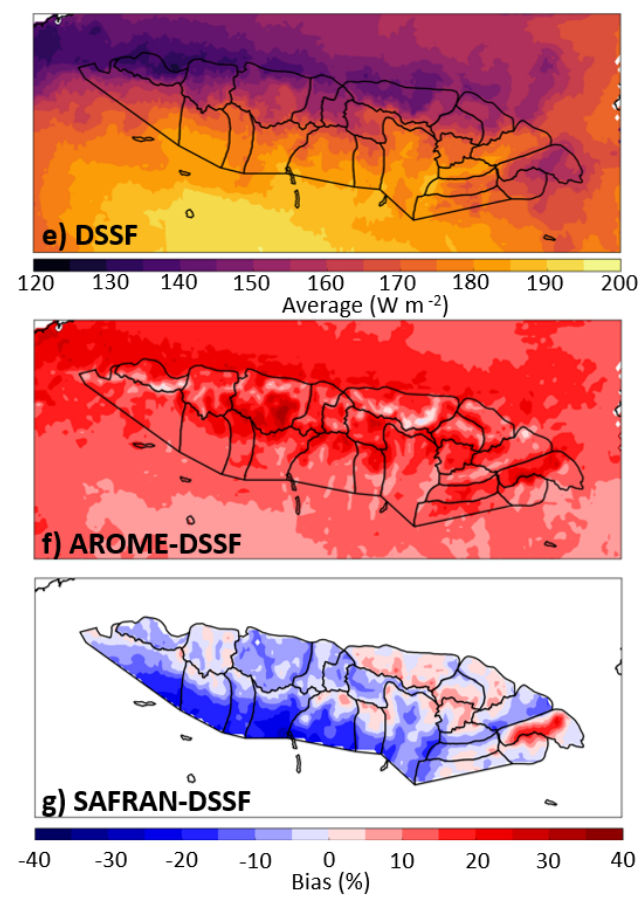

Figure 6. (a) Average of the DSLF from 1 August 2010 to 31 July 2014 in the Pyrenees, and relative difference with the DSLF for (b) AROME, (c) SAFRAN and (d) DSLFnew. (e) Average of the DSSF, and relative difference with the DSSF for (f) AROME and (g) SAFRAN.

where the clouds are often blocked, and the Spanish Pyrenees are often affected by Foehn wind and resulting clear sky conditions. The lowest DSSF values are found in the western part of the French Pyrenees, while the eastern part is more sunny due to the abating Atlantic influence and a Mediterranean climate. AROME presents a strong positive bias (Figs. $5 \mathrm{f}$ and $6 \mathrm{f}$ ), locally higher than $30 \%$ over the highest peaks, and still higher than $15 \%$ in many plain areas. The SAFRAN bias is very variable from one massif to another (Figs. $5 \mathrm{~g}$ and $6 \mathrm{~g}$ ). A strong negative bias for SAFRAN can be noticed in the south-western massifs of the Spanish Pyrenees (Fig. 6g), highlighting a poor representation of the orographic blocking as already noticed in Quéno et al. (2016).

The dependence of the different irradiance products on the altitude was further explored with the study of altitudinal gradients. Figure 7 represents the vertical evolution of the $\mathrm{LW} \downarrow$ and SW $\downarrow$ averaged over the SAFRAN massifs of the French Alps and the Pyrenees by steps of $100 \mathrm{~m}$ of elevation over the whole study period, together with the associated standard deviations.

The strong dependency of LW $\downarrow$ irradiance on altitude is confirmed in Fig. 7a for the French Alps and Fig. 7b for
Table 3. Mean altitudinal LW $\downarrow$ gradient for AROME, SAFRAN, DSLF and DSLFnew in the French Alps and the Pyrenees.

\begin{tabular}{lcccc}
\hline & AROME & SAFRAN & DSLF & DSLFnew \\
\hline French Alps & -29 & -21 & -31 & -36 \\
Pyrenees & -31 & -23 & -32 & -37 \\
\hline
\end{tabular}

the Pyrenees. As a reference, the altitudinal gradient for annual LW $\downarrow$ means of $-29 \mathrm{~W} \mathrm{~m}^{-2} \mathrm{~km}^{-1}$ found by Marty et al. (2002) in the Swiss Alps is plotted in dashed lines, while Table 3 lists the mean altitudinal gradient for each dataset in both domains. All datasets present a steady decrease in LW $\downarrow$ with altitude and are close to each other below approximately $1200 \mathrm{~m}$. For higher elevations, SAFRAN annual mean value is significantly stronger than AROME, DSLF and DSLFnew, due to a lower vertical gradient (Table 3). We showed in Sect. 3.1 that AROME, DSLF and DSLFnew had a negative bias at the four mountain stations. This effect may come from a vertical gradient that is too strong (Table 3). DSLFnew is larger than AROME and DSLF at all altitudes below approx- 

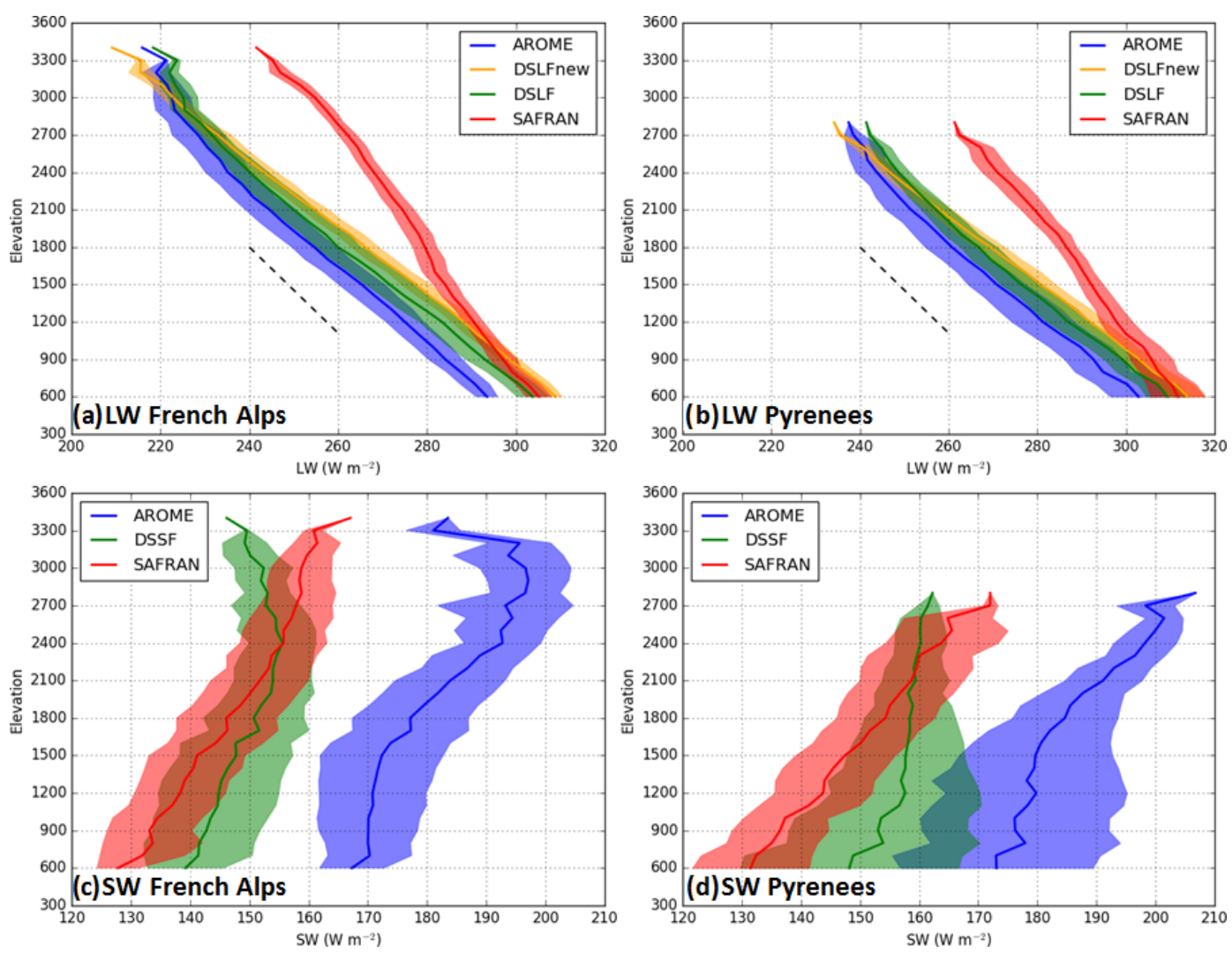

Figure 7. Vertical evolution by steps of $100 \mathrm{~m}$ : LW $\downarrow$ products (a) in the French Alps and (b) in the Pyrenees, and SW $\downarrow$ products (c) in the Alps and (d) in the Pyrenees, averaged over SAFRAN massifs from 1 August 2010 to 31 July 2014, with LSA SAF in green, AROME in blue, SAFRAN in red, DSLFnew in orange. The envelopes represent the mean \pm the standard deviation. The dashed black line represents the climatological $\mathrm{LW} \downarrow$ vertical gradient of $-29 \mathrm{~W} \mathrm{~m}^{-2} \mathrm{~km}^{-1}$ from Marty et al. (2002).

imately $2900 \mathrm{~m}$ in the French Alps (Fig. 7a) and $2200 \mathrm{~m}$ in the Pyrenees (Fig. 7b). It gets lower at the highest altitudes due to a stronger vertical gradient. The stronger vertical gradient of DSLFnew compared to DSLF is the confirmation that the use of forecasts of higher resolution for the algorithm takes the topography into account more. The excessive vertical gradient may originate from the cold bias of AROME near-surface temperatures, enhanced with the altitude (Vionnet et al., 2016), leading to a strong underestimation of the fluxes by DSLFnew at the highest altitudes.

In terms of $\mathrm{SW} \downarrow$ irradiance, Fig. 7c and d highlight that AROME fluxes are significantly stronger than SAFRAN and DSSF at all altitudes. SAFRAN is marked by an increase in incoming SW $\downarrow$ fluxes with altitude, while AROME and DSSF present a more variable evolution, and particularly a decrease in the fluxes at the highest altitudes in the Alps (Fig. 7c). This decrease may reflect the more frequent presence of clouds blocked by the highest peaks. Furthermore, these figures underline a weaker dependency of SW $\downarrow$ irradiance with altitude than $\mathrm{LW} \downarrow$ irradiance. Indeed, the standard deviation of LW $\downarrow$ at a given altitude is small compared to the total variation of the mean LW $\downarrow$ with altitude for all products (Fig. 7a and b), whereas they can reach sim- ilar values for $\mathrm{SW} \downarrow$ (Fig. 7c and d). This spatial variability at a given altitude is particularly marked at low- and midaltitudes $(<1800 \mathrm{~m})$ in the Pyrenees for AROME and DSSF, reflecting a good representation of the strong climate heterogeneity between French and Spanish foothills. SAFRAN, which gives homogeneous analyses for each massif, does not account for the spatial variability within the massif as is the case for AROME and DSSF.

\section{Impact of the irradiance products on snowpack simulations}

Snowpack simulations were performed over four winters from 2010 to 2014 to assess the impact of the different irradiance datasets as radiative forcing. Table 4 summarizes the bias and RMSE for the three simulations (A-Cro, AL-Cro and AS-Cro) compared at 172 stations of the French Alps and the Pyrenees over the period. The error statistics are aggregated by domain and elevation range. As shown by Vionnet et al. (2016) and Quéno et al. (2016), A-Cro overestimates the snow depth, with marked RMSE. This is due to several different reasons, further discussed in Sect. 5.3. The use of 
Table 4. Bias and root mean square error (RMSE) of snow depth at 172 stations of the French Alps and the Pyrenees over the period 20102014 for simulations A-Cro, AL-Cro and AS-Cro. The best metrics are given in bold.

\begin{tabular}{lcccccccc}
\hline Domain and & \multicolumn{3}{c}{ Bias $(\mathrm{cm})$} & & \multicolumn{3}{c}{ RMSE $(\mathrm{cm})$} \\
\cline { 2 - 4 } \cline { 7 - 8 } elevation range & A-Cro & AL-Cro & AS-Cro & & A-Cro & AL-Cro & AS-Cro \\
\hline French Alps & 38 & 43 & $\mathbf{2 9}$ & & 62 & 72 & $\mathbf{5 9}$ \\
$<1800 \mathrm{~m}$ & 31 & 29 & $\mathbf{2 4}$ & & 52 & 53 & $\mathbf{4 9}$ \\
{$[1800,2200 \mathrm{~m})$} & 26 & 26 & $\mathbf{1 2}$ & & $\mathbf{5 8}$ & 66 & 59 \\
$\geq 2200 \mathrm{~m}$ & 61 & 80 & $\mathbf{5 3}$ & & 79 & 99 & $\mathbf{7 2}$ \\
\hline Pyrenees & 55 & 70 & $\mathbf{5 1}$ & & 89 & 106 & $\mathbf{8 8}$ \\
$<1800 \mathrm{~m}$ & 66 & 72 & $\mathbf{5 9}$ & & 97 & 105 & $\mathbf{9 1}$ \\
{$[1800,2200 \mathrm{~m})$} & 46 & 63 & $\mathbf{4 3}$ & & $\mathbf{8 5}$ & 105 & 86 \\
$\geq 2200 \mathrm{~m}$ & 57 & 78 & $\mathbf{5 6}$ & & $\mathbf{8 7}$ & 109 & 89 \\
\hline
\end{tabular}

DSSF and DSLFnew as radiative forcing (AL-Cro) increases the bias and the RMSE in the French Alps and the Pyrenees. On the contrary, the use of SAFRAN radiative forcing (AS-Cro) gives a lower bias and RMSE in both massifs. The highest biases and RMSE are reached at high altitudes ( $\geq 2200 \mathrm{~m}$ ) by AL-Cro, because of the marked underestimation of DSSF and DSLFnew at these elevations. The use of SAFRAN irradiances (AS-Cro) tends to reduce the biases of A-Cro, particularly at the lowest elevations where the higher $\mathrm{LW} \downarrow$ increases the melting during the whole season. Above $1800 \mathrm{~m}$, the RMSE is not reduced by the use of SAFRAN irradiances (except above $2200 \mathrm{~m}$ in the Alps), because the higher LW $\downarrow$ enhances the melting in winter and the lower $\mathrm{SW} \downarrow$ reduces the melting in spring, which increases the dispersion around the annual bias.

Figure 8 provides an example of snow depth evolution at Albeille station in the French Pyrenees ( $2195 \mathrm{~m}$; location shown in Fig. 9) during one year (2010-2011), as observed and simulated in the three configurations. The behaviour of the models at this station is typical of most of the stations. The three simulations overestimate the snow depth. AL-Cro presents the strongest positive bias during the whole season, because of lower values of LW $\downarrow$ and SW $\downarrow$. On the contrary, AS-Cro exhibits a lower overestimation than the other simulations during all of the accumulation period (until midMarch approximately). It can be explained by the values of SAFRAN LW $\downarrow$ irradiance, which are higher than the other datasets. In winter, $\mathrm{SW} \downarrow$ irradiances are low and the snow albedo is high: their contribution to the surface energy budget is much lower than in spring. Thus, LW $\downarrow$ irradiances have a higher relative contribution during the accumulation period. However, during the melting period (from mid-March to mid-May here), the contribution of SW $\downarrow$ irradiances is the highest, due to higher extra-terrestrial solar fluxes, longer days and lower snow albedo: because of their higher SW $\downarrow$, A-Cro simulations melt faster than AS-Cro, which reduces their bias.

These trends can also be observed when looking at maps of spatially distributed snowpack simulations. Figure 9 repre-

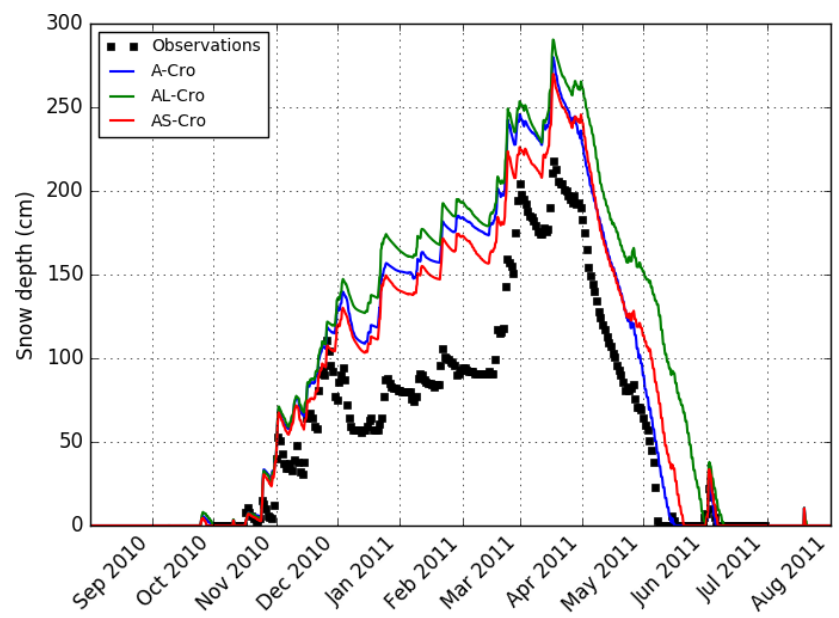

Figure 8. Snow depth evolution at Albeille station (2195 m, French Pyrenees) during winter 2010-2011: observations in black, A-Cro simulation in blue, AL-Cro in green, AS-Cro in red.

sents the SWE (snow water equivalent) simulated by A-Cro taken as a reference on 1 February 2013 during the accumulation period and on 1 May 2013 during the melting period, and the differences between AL-Cro, AS-Cro and this reference at the same dates. The differences with AL-Cro are generally between -50 and $+50 \mathrm{~mm}$ on 1 February 2013 . AS-Cro exhibits lower SWE values at this date, due to its higher LW $\downarrow$ irradiance. However, on 1 May 2013, both simulations exhibit higher SWE values than A-Cro almost everywhere, with differences mostly higher than $200 \mathrm{~mm}$, locally reaching $400 \mathrm{~mm}$, due to lower $\mathrm{SW} \downarrow$ irradiances.

The impact of the radiative forcing on SWE simulations was further studied at two grid points in the French Pyrenees: one at low altitude (point A, $1359 \mathrm{~m}$ ) and one at high altitude (point B, $2459 \mathrm{~m}$ ), both located in Fig. 9. Contrary to snow depth, comparing SWE simulations enables the study of the impact of the different radiative forcing datasets on the snowpack mass balance with no additional uncertainty on snow compaction. Figure 10 represents the 


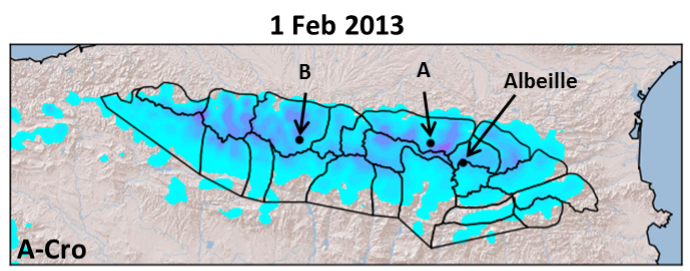

(a)

(c)

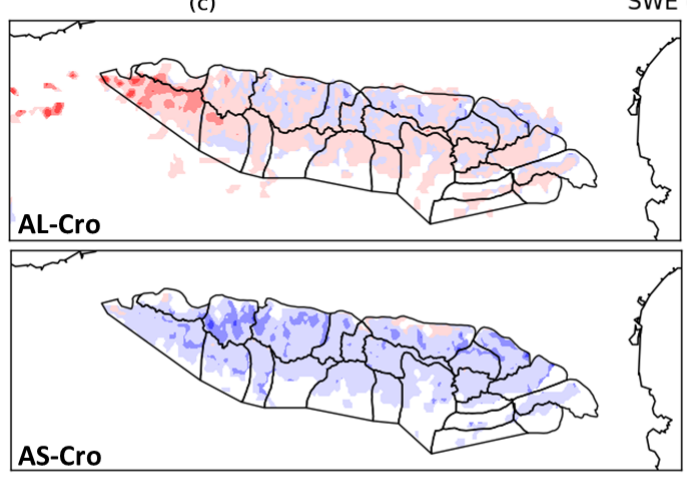

(e)

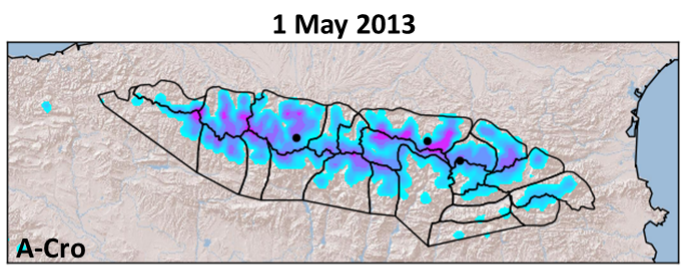

(b)

(d)

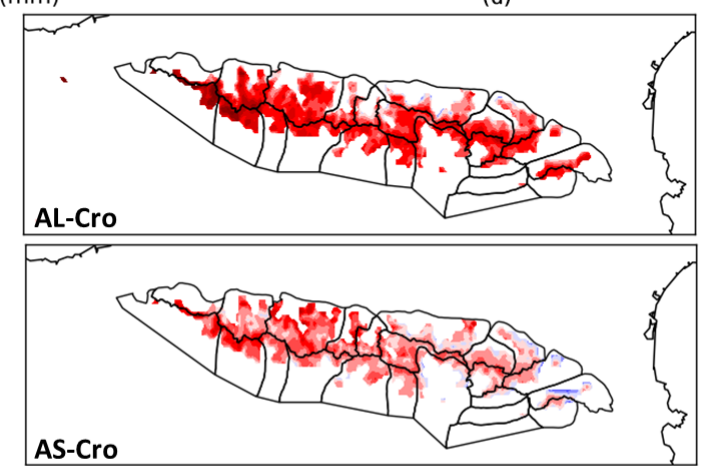

(f)

Figure 9. Snow water equivalent simulated by A-Cro (a, b) on 1 February 2013 (a, c, e) and 1 May 2013 (b, d, f) over the Pyrenees. Differences between the SWE simulated by AL-Cro (c, d) and AS-Cro (e, f) with A-Cro at the same dates. Points A and B and Albeille station are indicated by black dots.

simulated SWE and cumulated melting at point A during the winter season 2010-2011, together with the difference in irradiance with AROME as reference. The same evolutions at point $\mathrm{B}$ are represented in Fig. 11. The relative impact of DSSF and DSLFnew is represented in dashed lines (simulations $\mathrm{AL}_{\mathrm{SW}}-\mathrm{Cro}$ and $\mathrm{AL}_{\mathrm{LW}}-\mathrm{Cro}$, as defined in Table 2). At point A, melting occurs during the winter. Consequently, AS-Cro and $\mathrm{AL}_{\mathrm{LW}}$-Cro simulations lead to lower values of SWE than A-Cro, since they both exhibit higher $\mathrm{LW} \downarrow$ than AROME $\left(+8 \mathrm{~W} \mathrm{~m}^{-2}\right.$ for DSLFnew and $+9 \mathrm{~W} \mathrm{~m}^{-2}$ for SAFRAN). Thus, on 15 February 2011, the cumulated melting is more than doubled for AL-Cro (104 mm, and $154 \mathrm{~mm}$ for $\mathrm{AL}_{\mathrm{LW}}-\mathrm{Cro}$ ) compared to A-Cro $(42 \mathrm{~mm})$. The lower SW $\downarrow$ of DSSF compared to AROME $\left(-15 \mathrm{~W} \mathrm{~m}^{-2}\right)$ implies very limited SWE differences to ACro in the heart of the winter (same cumulated melting for A-Cro and $\mathrm{AL}_{\mathrm{SW}}$-Cro on 15 February 2011). Similarly, the lower SW $\downarrow$ of SAFRAN $\left(-3 \mathrm{~W} \mathrm{~m}^{-2}\right)$ cannot compensate the higher LW $\downarrow$ during the winter. The simulation using both DSSF and DSLFnew irradiances (AL-Cro) is intermediate between both curves $\left(\mathrm{AL}_{\mathrm{LW}}-\mathrm{Cro}\right.$ and $\left.\mathrm{AL}_{\mathrm{SW}}-\mathrm{Cro}\right)$. At high altitude (Fig. 11), the melting period starts at the beginning of April. Thus, there are no differences between all simulations until then, despite strong differences in the radiative forcing. Snow melts slightly more slowly with SAFRAN radiative forcing, the lower SW $\downarrow$ being counterbalanced by the higher LW $\downarrow$. A marked difference in the melt timing can be noted for AL-Cro: the lower SW $\downarrow$ is not counterbalanced by the slightly higher $L W \downarrow$. The peak SWE is shifted by almost 1 month compared to A-Cro. Therefore, it leads to marked differences in terms of cumulated melting: on 1 June 2011, the cumulated melting for A-Cro reaches $1149 \mathrm{~mm}$, i.e. almost the double of AL-Cro (613, and $433 \mathrm{~mm}$ for ALswCro). The simulation mixing DSSF and DSLFnew irradiances (AL-Cro) is very close to the DSSF-only simulation $\left(\mathrm{AL}_{\mathrm{SW}}\right.$-Cro). Overall, the effect of DSSF prevails at high altitude leading to a later end of the snow cover, while the effect of DSLFnew prevails at low altitude leading to an earlier end of the snow cover.

\section{Discussion}

\subsection{Quality of irradiance datasets in mountainous terrain}

We presented an overview of the quality of several irradiance datasets through an in-depth assessment of the irradiance fields in mountainous terrain. In terms of $\mathrm{SW} \downarrow$ irradiances, DSSF exhibits the best metrics in mountains, particularly below $2000 \mathrm{~m}$. Above $2000 \mathrm{~m}$, its RMSE is similar to SAFRAN and AROME, due to a strong negative bias. AROME presents systematic and large overestimations of SW $\downarrow$ irradiances, contrarily to SAFRAN's tendency to underestimate them. 


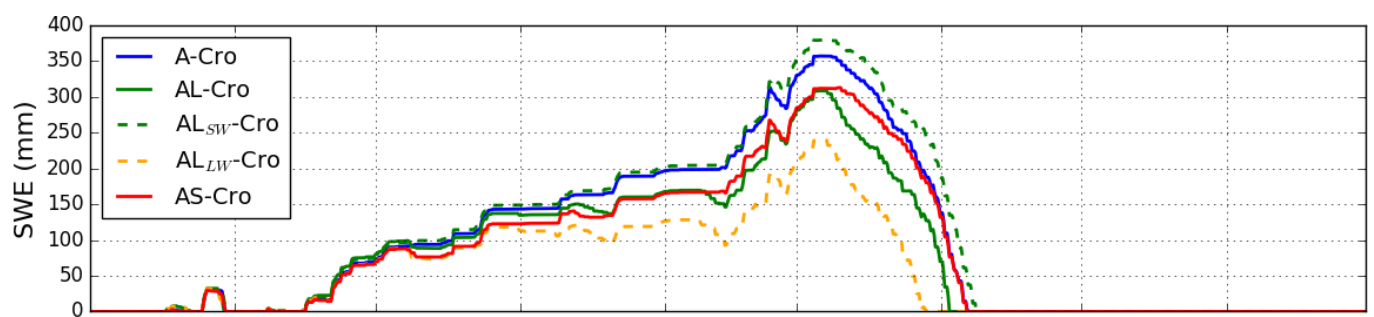

(a)

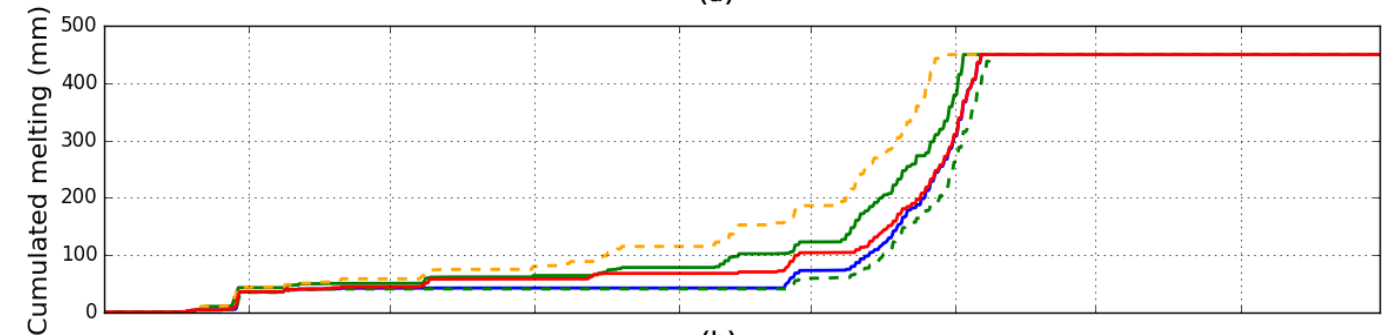

(b)

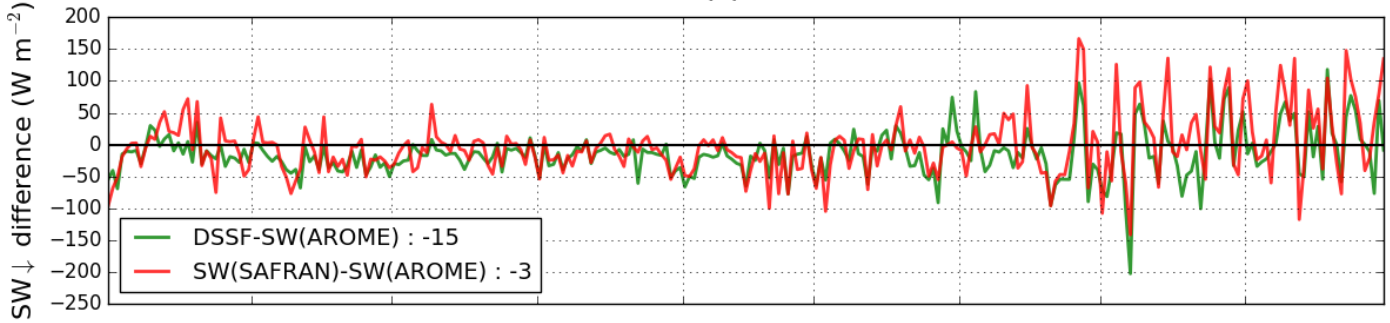

(c)

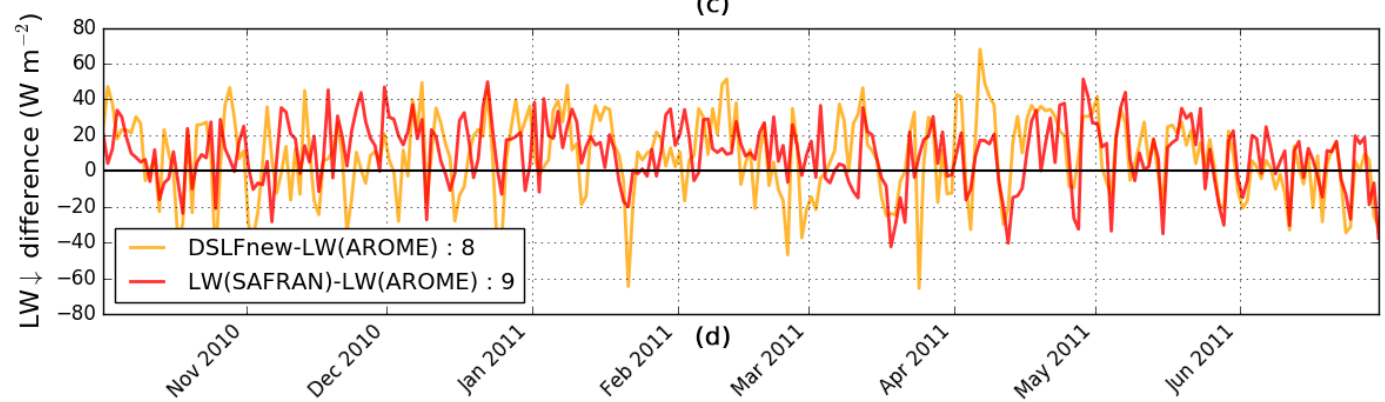

Figure 10. (a) Snow water equivalent simulated by A-Cro (blue), AL-Cro (green), AL $\mathrm{L}_{\mathrm{SW}}$ (dashed green), $\mathrm{AL}_{\mathrm{LW}}$ (dashed orange) and ASCro (red) from 1 October 2010 to 30 June 2011 at point A in the Pyrenees (1359 m, Fig. 9). (b) Cumulated melting represented with the same colours. (c, d) Mean daily irradiance differences with AROME for DSSF (green), DSLFnew (orange) and SAFRAN irradiances (red).

The spatial variations of SW $\downarrow$ irradiances are better represented in DSSF and AROME than in SAFRAN. In terms of $\mathrm{LW} \downarrow$ irradiances, the obtained errors are comparable and it is difficult to identify the best product. The use of forecasts at higher spatial resolution to compute DSLFnew enhances the topographic dependence, which limits the underestimation of LW $\downarrow$ irradiance at low and mid-altitudes found with DSLF but strengthens the negative bias at high altitude. The resulting altitudinal gradient is probably too strong. It may originate from the cold bias of AROME near-surface temperatures, enhanced with the altitude (Vionnet et al., 2016), which leads to a strong underestimation of the fluxes by DSLFnew at the highest altitudes.

Several studies evaluated LSA SAF irradiance products at hourly time steps (when the sun is above the horizon for
SW $\downarrow)$ at plain stations. For DSSF, we showed in this study a bias of $-14 \mathrm{~W} \mathrm{~m}^{-2}$ and a RMSE of $117 \mathrm{~W} \mathrm{~m}^{-2}$ (Fig. 2), while for plains, Geiger et al. (2008b), Ineichen et al. (2009) and Cristóbal and Anderson (2013) reported biases of +2 , +5 and $-5 \mathrm{~W} \mathrm{~m}^{-2}$ respectively, and RMSE of 87,103 and $65 \mathrm{~W} \mathrm{~m}^{-2}$ respectively. The higher RMSE in mountains may partly be explained by higher mean values. For DSLF, we showed in this study a bias of $-8 \mathrm{~W} \mathrm{~m}^{-2}$ and a RMSE of $32 \mathrm{~W} \mathrm{~m}^{-2}$ (Fig. 3), while for plains, Trigo et al. (2010) and Ineichen et al. (2009) reported biases of +3 and $-11 \mathrm{~W} \mathrm{~m}^{-2}$ respectively, and RMSE of 25 and $29 \mathrm{~W} \mathrm{~m}^{-2}$ respectively. The error statistics for mountains are close to those for plains and lie within the range of uncertainty of LW $\downarrow$ sensors in mountains (Table 1). Thus, the performance of LSA SAF irradiance products remains satisfactory compared to previ- 


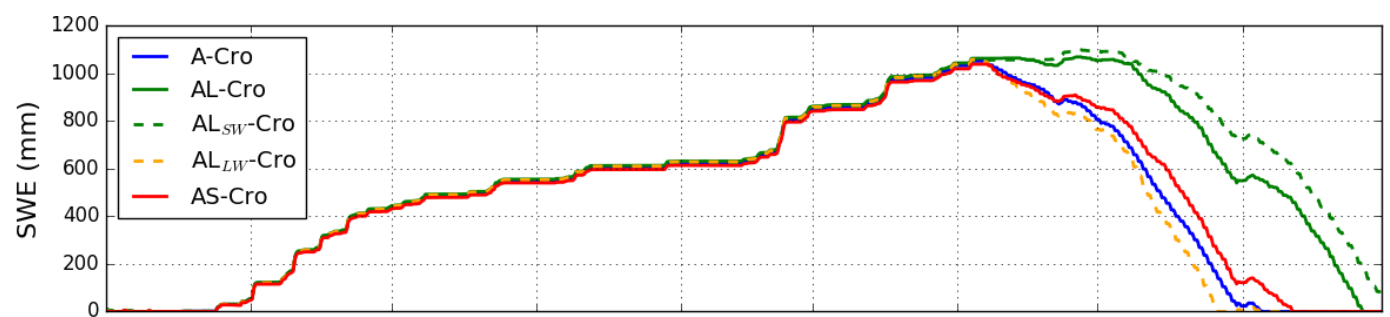

(a)

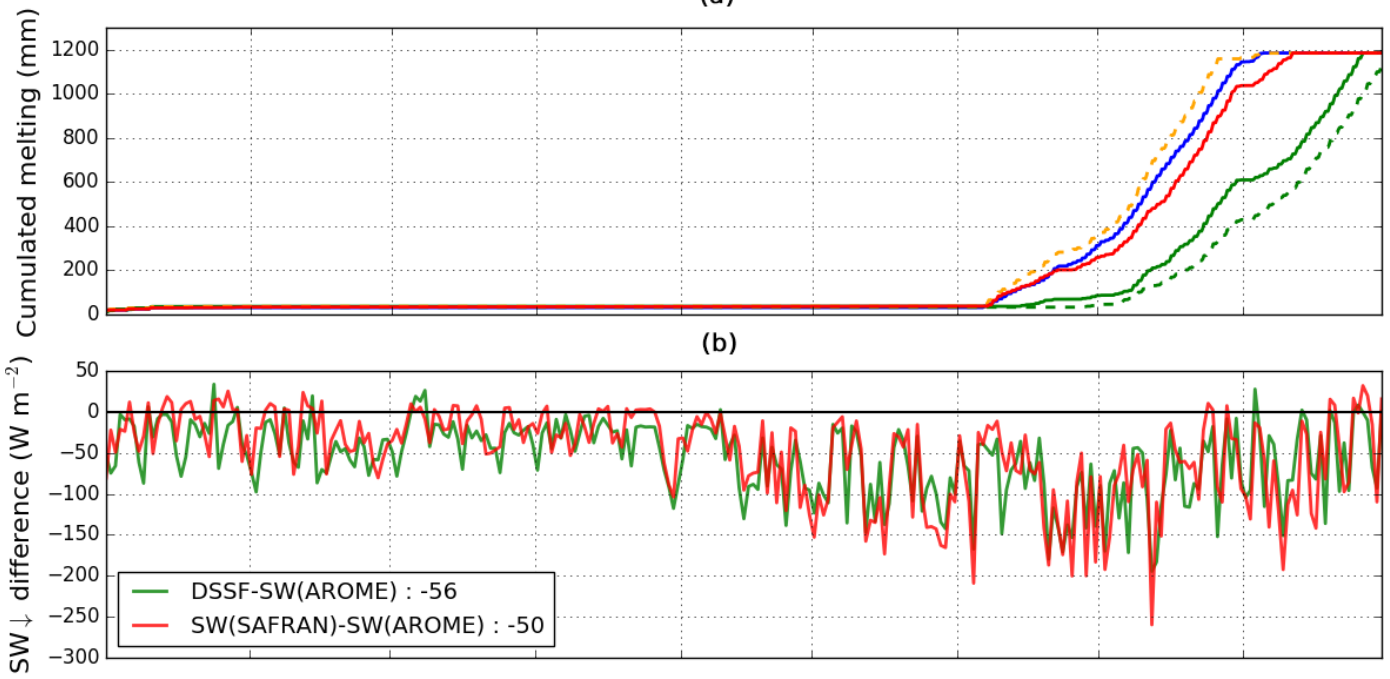

(c)

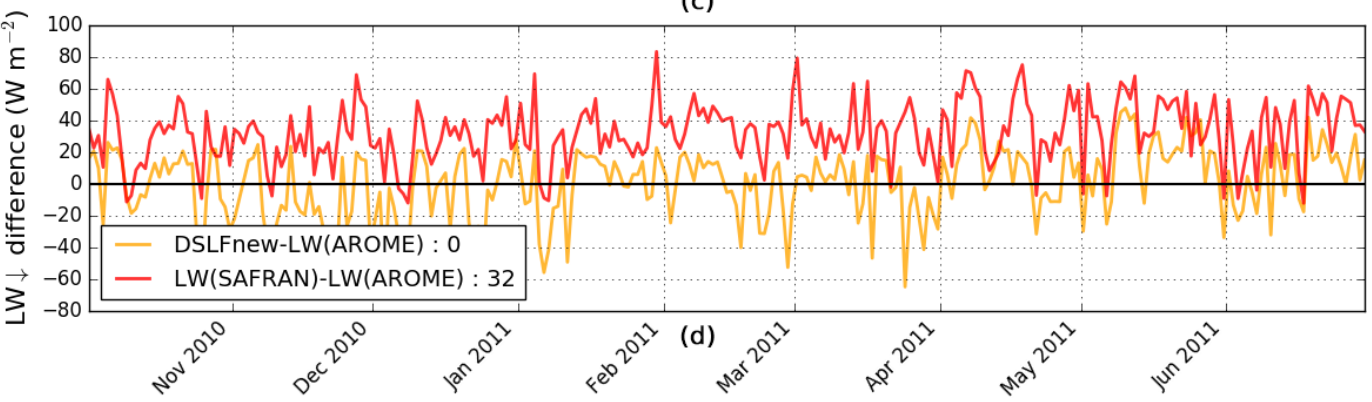

Figure 11. (a) Snow water equivalent simulated by A-Cro (blue), AL-Cro (green), AL $\mathrm{SW}$ (dashed green), $\mathrm{AL}_{\mathrm{LW}}$ (dashed orange) and ASCro (red) from 1 October 2010 to 30 June 2011 at point B in the Pyrenees (2459 m, Fig. 9). (b) Cumulated melting represented with the same colours. (c, d) Mean daily irradiance differences with AROME for DSSF (green), DSLFnew (orange) and SAFRAN irradiances (red).

ous evaluations of these products on plains, even though they generally do not reach the target accuracy (Sect. 2.2.3), derived from reference plain stations.

Hinkelman et al. (2015) similarly evaluated the CERES SYN products at mountain stations for $3 \mathrm{~h}$ averages. In terms of SW $\downarrow$ irradiance, they showed biases between -13 and $+51 \mathrm{~W} \mathrm{~m}^{-2}$ and RMSE between 93 and $162 \mathrm{~W} \mathrm{~m}^{-2}$. In terms of LW $\downarrow$ irradiance, they showed biases between -17 and $+31 \mathrm{~W} \mathrm{~m}^{-2}$ and RMSE between 24 and $40 \mathrm{~W} \mathrm{~m}^{-2}$. Despite a coarser spatial resolution, the obtained irradiance errors are similar to those of LSA SAF products, but they are reduced by the $3 \mathrm{~h}$ average. Reaching a similar performance at hourly time steps can then be considered as an improvement. The shorter time step of LSA SAF products also enables a finer representation of the $\mathrm{SW} \downarrow$ diurnal cycle.
These results suggest that LSA SAF satellite-derived estimates of SW $\downarrow$ and $\mathrm{LW} \downarrow$ irradiances are suitable to drive distributed snowpack simulations in mountainous terrain. DSLF can be replaced by DSLFnew up to mid-altitudes $(2200 \mathrm{~m}$ approximately), where the performance is improved. These products constitute beneficial alternatives to NWP and analysis systems in complex terrain.

\subsection{Limitations due to the topographical influence on radiation}

Limitations to the use of kilometric-resolution irradiance products in complex terrain arise from the high topographical influence on incoming radiation. These limitations are tackled here following three axes: (i) limitations of satellite- 
derived irradiance products in mountainous terrain, (ii) local topographical effects on radiation in the radiative forcing of snowpack simulations, and (iii) influence of local topography on the evaluation of the irradiance products and snowpack simulations.

First, satellite data sometimes require corrections when applied over mountains. For instance, the HelioMont solar irradiance product (Stöckli, 2013; Castelli et al., 2014) is calculated using the MSG SEVIRI High Resolution Visible (HRV; 0.45-1.1 $\mu \mathrm{m}$ ) channel and five other near-infrared and infrared channels $(0.6,0.8,1.6,10.8,12.0 \mu \mathrm{m})$. In this method, the satellite data depending on the HRV channel (at $1 \mathrm{~km}$ resolution) require an orthorectification to avoid artificial geometric shifts in terrain due to its high resolution compared to the terrain elevation (Stöckli, 2013), while the satellite data from the other channels (at MSG pixel resolution, i.e. more than $3 \mathrm{~km}$ ) are not orthorectified. The DSSF and the DSLF only use data from the $0.6,0.8$ and $1.6 \mu \mathrm{m}$ channels, which do not require orthorectification, similarly to the HelioMont method. Corrections may also be applied to the meteorological inputs. The DSSF does not rely as much as the DSLF on meteorological forecasts but it still uses the total column water vapour content (TCWV) forecast from ECMWF IFS at $16 \mathrm{~km}$ resolution. Since the TCWV is dependent on the elevation, the DSSF could be improved with AROME forecasts of TCWV at kilometric resolution, similarly to DSLFnew. Despite that, the DSSF still exhibits a better performance than AROME and SAFRAN in mountains.

At sub-kilometric scale, the local topography strongly influences the solar and longwave irradiance variability. Oliphant et al. (2003) identified the following surface characteristics as causes of radiative flux variability, by order of importance: slope aspect, slope angle, elevation, albedo, shading, sky view factor (SVF) and leaf area index. These local factors are not taken into account in AROME, SAFRAN and LSA SAF irradiance products. This study aims at assessing the practical benefits of different irradiance datasets to be used as radiative forcing for distributed snowpack simulations at $2.5 \mathrm{~km}$ resolution in mountains. In the context of representing the mean state of the snowpack over a considered flat pixel, at a given altitude and a given location in the mountain range, the terrain influence on the radiation does not need to be taken into account in the radiative forcing. However, to capture the sub-kilometric variability of the snowpack, it will be necessary to consider sub-grid effects of the surrounding terrain on the radiation, and thus a topographical correction of irradiance products (e.g. Helbig and Löwe, 2012) such as that applied to MSG satellite-derived solar fluxes by the HelioMont method (Stöckli, 2013; Castelli et al., 2014).

The main limitation implied by local topography effects regards the evaluation of the irradiance products and the snowpack simulations through in situ comparisons. Indeed, in situ irradiance and snow depth measurements are affected by these effects. The location of stations in flat and open fields reduces the impacts of slope, aspect and vegetation.
The evaluation of solar irradiances at periods when the sun is not masked by the surrounding topography enables the terrain shadowing effect on direct solar radiation to be discarded. However, this effect is not considered for snow depth comparisons. Additionally, the limited sky view and the reflection effects on diffuse solar radiation are not taken into account, and neither are the limited sky view and terrain thermal radiation effects on longwave irradiance. According to the incoming radiation budget accounting for topography effects on a flat surface (e.g. Müller and Scherer, 2005), the bias for not taking into account the SVF in the shortwave irradiance is $\left.(1-\mathrm{SVF}) \cdot\left(\mathrm{SW}_{\mathrm{dif}}-\mathrm{SW}_{\text {ref }}\right)\right)$, where $\mathrm{SW}_{\mathrm{dif}}$ is the diffuse shortwave irradiance and $\mathrm{SW}_{\text {ref }}$ is the terrainreflected shortwave radiation. This bias is small in clear-sky conditions, because the SVF contribution is then significantly lower than topographic shading (e.g. Olson et al., 2019), but it increases in cloudy conditions with a stronger relative contribution of $\mathrm{SW}_{\mathrm{dif}}$. The bias for not taking into account the SVF in the longwave irradiance is $(1-\mathrm{SVF}) \cdot\left(\mathrm{LW}_{\mathrm{atm}}-\right.$ $\mathrm{LW}_{\text {ter }}$ ), where $\mathrm{LW}_{\mathrm{atm}}$ is the atmospheric longwave irradiance and $\mathrm{LW}_{\text {ter }}$ is the terrain thermal radiation. This bias is more significant when $\mathrm{LW}_{\mathrm{atm}}$ is low (Sicart et al., 2006) but is usually small compared to $\mathrm{LW}_{\mathrm{atm}}$ on horizontal surfaces (Plüss and Ohmura, 1997), which is the case of the measurement locations.

\subsection{Sensitivity of snowpack simulations to the radiative forcing}

DSSF and DSLFnew irradiance datasets were used to replace AROME irradiance forecasts as radiative forcing of Crocus simulations. The rest of the atmospheric forcing was taken from AROME forecasts. A similar experiment was done with SAFRAN irradiances. The performance of the snowpack simulations was degraded when using DSSF and DSLFnew products, with an increased positive snow depth bias. On the contrary, the use of SAFRAN irradiances was found to decrease the positive bias obtained with AROMECrocus. Vionnet et al. (2016) and Quéno et al. (2016) already showed an overestimation of snow depth by AROME-Crocus in the French Alps and the Pyrenees respectively. In addition, Quéno et al. (2016) partly attributed this overestimation to an underestimation of strong melting. Thus, replacing AROME irradiance forecasts by lower or equivalent values (DSSF and DSLFnew) logically enhances the overestimation, despite the better quality of the new irradiance products. In this case, improving the radiative forcing leads to degraded snowpack simulations, which is consistent with the strong interaction effect in snowpack simulations highlighted by Günther et al. (2019). This effect may be attributed to error compensations within the atmospheric forcing and/or within the snowpack model:

- Quéno et al. (2016) showed that the positive snow depth bias is not due to an overestimation of daily snowfall by AROME-Crocus. The strong overestimation of SW $\downarrow$ 
by AROME shown in this study would also tend to increase the melting and reduce the snow depth bias. We showed here it is not counterbalanced by the underestimation of LW $\downarrow$. However, the underestimated melting may be linked to an underestimation of the turbulent fluxes. It may have several causes that need to be further explored, e.g. a possible influence of the $T_{2 \mathrm{~m}}$ cold bias, particularly marked at the highest altitudes ( $-2.8 \mathrm{~K}$ above $2500 \mathrm{~m}$; Vionnet et al., 2016).

- Within the snowpack model Crocus, Quéno et al. (2016) showed an underestimation of snow settling, with a direct effect on snow depth bias. The snow compaction scheme used in Crocus depends on the weight of overlying snow, temperature and density of snow, liquid water content, and snow grain size (Vionnet et al., 2012). The parameterization of the albedo evolution also needs to be questioned: Lafaysse et al. (2017) underlined a positive bias of Crocus-simulated albedo at Col de Porte (Fig. 1a), which they partly attributed to the parameterization of albedo decrease in the visible range as a function of the age of the snow layer and the altitude of the site. An overestimation of the albedo indeed decreases the absorption of solar energy, hence enhancing the positive snow depth bias.

These results endorse the idea that snowpack ensemble simulations are necessary to mitigate error compensations, as recently developed for Crocus with the multiphysical ensemble system ESCROC (Ensemble System Crocus; Lafaysse et al., 2017).

The sensitivity of Crocus snowpack simulations to the radiative forcing can be interpreted in the light of several works quantifying the impact of atmospheric forcing errors on snowpack simulations (Raleigh et al., 2015; Lapo et al., 2015b; Sauter and Obleitner, 2015). First, Sauter and Obleitner (2015) studied the influence of uncertainties on atmospheric forcing variables on simulations of glacier massbalance using Crocus in the Svalbard islands (European Arctic). They identified LW $\downarrow$ uncertainty as the main source of variance $(50 \%)$ of the surface energy balance throughout the year. However, the prevailing effect of LW $\downarrow$ compared to $\mathrm{SW} \downarrow$ is more marked at high latitudes, because of the lack of solar insolation in winter. In our study, we showed that the new LW $\downarrow$ forcing from DSLFnew (with a positive bias compared to AROME) had a significant impact on the mass budget during the whole winter at low altitudes (Fig. 10), while the impact was more limited at high altitudes (Fig. 11). It can be explained by decreasing LW $\downarrow$ irradiances with altitude together with increasing SW $\downarrow$ irradiances, leading to a more significant impact of SW $\downarrow$ at high altitudes. It is also due to the earlier snowmelt at low altitudes, which limits the crucial role played by $S W \downarrow$ in spring.

Furthermore, the differences between the different radiative forcing datasets mainly consist of biases rather than random errors: a typical example is the difference between
AROME and DSSF in SW $\downarrow$ at high altitudes, shown in Fig. 11. Their effect is then cumulated during the whole season, rather than counterbalanced, which increases their impact. It is consistent with the outcomes of Raleigh et al. (2015) who showed that snowpack models are more sensitive to biases than random errors in the forcings. It was particularly highlighted for incoming radiative fluxes by Lapo et al. (2015b). Finally, although the SWE is not impacted by the differences in incoming radiative fluxes at high altitude during the accumulation period (Fig. 11), impacts are to be expected in terms of snow surface temperatures, with possible consequences on the snow metamorphism processes. Lapo et al. (2015b) indeed showed more sensitivity of the snowpack simulations to irradiance errors at the coldest sites when evaluated in terms of snow surface temperature rather than SWE. Future works could thus focus on the impact of the different incoming radiative flux datasets on the surface energy budget and the resulting effects on the snowpack stratigraphy.

\section{Conclusions}

In this paper, we assessed the quality of satellite-derived incoming radiative flux products (DSSF for solar irradiance and DSLF for longwave irradiance) in mountainous terrain, by conducting a thorough inter-comparison study involving kilometric resolution forecasts from the NWP system AROME and fields from the SAFRAN analysis system. A new satellite-derived product for $L W \downarrow$ irradiance (DSLFnew) was developed using the DSLF algorithm fed by AROME forecasts. An evaluation of all available products was performed against in situ measurements using four years of data in the French Alps and the Pyrenees. The resulting analysis showed that DSSF products are best for solar irradiance, despite an underestimation at the highest altitudes, while AROME is associated with a strong positive bias and SAFRAN with a negative bias. In terms of longwave irradiance, contrasted results were obtained at the mountain stations, all falling within the range of uncertainty of sensors. A systematic underestimation by AROME, DSLF and DSLFnew was highlighted. The negative bias of DSLF was reduced by DSLFnew up to mid-altitudes but enhanced at high altitudes due to an overly strong altitudinal gradient associated with the cold bias in AROME near-surface air temperature at high altitudes. A spatial comparison of the datasets showed that AROME and DSSF better represent the spatial variability of $S W \downarrow$ fluxes in mountains by comparison with SAFRAN. These results are encouraging and highlight the potential benefits of using DSSF, DSLF and DSLFnew as radiative forcing for snowpack modelling in mountainous terrain. Their relatively good quality in mountains as compared to lower altitudes also supports the use of these data as climatological inputs and/or validation datasets for NWP 
models over complex domains such as mountains, where incoming radiative flux measurements are scarce.

An evaluation of distributed snowpack simulations by Crocus driven by AROME and the different irradiance datasets was then conducted in the French Alps and the Pyrenees. We showed that replacing AROME irradiances by DSSF and DSLFnew increased the positive bias of snow depth, despite an overall better performance of these datasets in terms of incoming radiative fluxes. Therefore, an improved meteorological forcing does not ensure more accurate snowpack simulations. This is mostly due to error compensations within the atmospheric forcing and the snowpack model. Complementary studies are sorely needed to identify the cause of the underestimated melting, which cannot be attributed to radiative fluxes. They should tackle factors such as the turbulent fluxes simulated by AROME-Crocus and the albedo parametrization in Crocus. Multiphysical ensemble snowpack modelling would also enable simulation errors to be accounted for (Lafaysse et al., 2017). Until such improvements are performed in the AROME-Crocus modelling context, the LSA SAF products of incoming radiative fluxes can be used to improve understanding of snowpack models as well as in other snowpack-related studies, because they provide irradiance data of reasonable quality in mountainous areas.

Data availability. Irradiance datasets are available from the following sources:

- DSSF and DSLF were provided by the EUMETSAT Satellite Application Facility on Land Surface Analysis (LSA SAF; Trigo et al., 2011; http://lsa-saf.eumetsat.int, last access: 23 April 2020).

- AROME forecasts in real time are publicly available at https:// donneespubliques.meteofrance.fr (last access: 23 April 2020). All AROME forecast archives are available on request from the same website for a data provision fee. The AROME and SAFRAN database used in this study is available for research purposes on request from the authors.

- Shortwave and longwave irradiance in situ measurements from the Météo-France station network are available for a data provision fee at https://donneespubliques.meteofrance.fr (last access: 23 April 2020). The measurements covering the domain and period used in this study are available for research purposes on request from the authors. Irradiance measurements from Argentière glacier and Saint-Sorlin glacier AWSs are available at http://data.cryobsclim.fr (last access: 23 April 2020). Irradiance measurements from Bassiès AWS were provided by Centre d'Etudes Spatiales de la Biosphère: they should be contacted directly for data access.

Snowpack datasets are available from the following sources:

- SURFEX/ISBA-Crocus model source code is available at https://opensource.umr-cnrm.fr/projects/surfex (last access: 23 April 2020).

- Snow depth measurements from Météo-France stations are publicly available at https://donneespubliques.meteofrance.fr (last access: 23 April 2020). Additional snow depth measurements in the Pyrenees were also provided by Confederación Hidrográfica del Ebro, Servei Meteorològic de Catalunya, Centre d'Etudes Spatiales de la Biosphère and Instituto Pirenaico de Ecología: they should be contacted directly for data access.

Author contributions. FK, VV and LQ designed the study. LQ was responsible for the modelling strategy and the preparation of the paper. FK, VV and IDE helped to analyse the results. All authors contributed to the writing of the paper.

Competing interests. The authors declare that they have no conflict of interest.

Acknowledgements. DSSF and DSLF were provided by the EUMETSAT Satellite Application Facility on Land Surface Analysis (LSA SAF; Trigo et al., 2011). The authors are grateful to Simon Gascoin (CESBIO) for providing irradiance measurements from the Bassiès AWS, and to Delphine Six (IGE) for providing irradiance measurements from Saint-Sorlin glacier and Argentière glacier AWSs (data from GLACIOCLIM program, https://glacioclim.osug.fr, last access: 20 April 2020). We also thank Dominique Carrer, Jean-Louis Roujean and Catherine Meurey (CNRM) for help with the LSA SAF data, and Isabel Trigo (IPMA) for information about the DSLF algorithm. CNRM/CEN is part of LabEx OSUG@2020 (ANR10 LABX56). We are also grateful to the anonymous reviewers for their detailed comments which helped improve the paper.

Review statement. This paper was edited by Harrie-Jan Hendricks Franssen and reviewed by four anonymous referees.

\section{References}

Anderton, S. P., White, S. M., and Alvera, B.: Micro-scale spatial variability and the timing of snow melt runoff in a high mountain catchment, J. Hydrol., 268, 158-176, https://doi.org/10.1016/S0022-1694(02)00179-8, 2002.

Armstrong, R. and Brun, E.: Snow and climate: physical processes, surface energy exchange and modeling, Cambridge University Press, Cambridge, available at: http://www.cambridge.org/gb/academic/subjects/earth-andenvironmental-science/climatology-and-climate-change/snowand-climate-physical-processes-surface-energy-exchange (last access: 20 April 2020), 2008.

Bellaire, S., Katurji, M., Schulmann, T., and Hobman, A.: Towards a High-Resolution Operational Forecasting Tool for the Southern Alps - New Zealand, in: Proceedings of the International Snow Science Workshop, Banff, Canada, 388-393, https://doi.org/10.13140/2.1.3376.8640, 2014.

Brisson, A., Borgne, P. L., and Marsouin, A.: Development of Algorithms for Surface Solar Irradiance Retrieval at O\&SI SAF 
Low and Mid Latitudes, Tech. rep., Météo-France/CMS, Lannion, 1999.

Brousseau, P., Seity, Y., Ricard, D., and Léger, J.: Improvement of the forecast of convective activity from the AROMEFrance system, Q. J. Roy. Meteorol. Soc., 142, 2231-2243, https://doi.org/10.1002/qj.2822, 2016.

Brun, E., David, P., Sudul, M., and Brunot, G.: A numerical model to simulate snow-cover stratigraphy for operational avalanche forecasting, J. Glaciol., 38, 13-22, https://doi.org/10.1017/S0022143000009552, 1992.

Carrer, D., Lafont, S., Roujean, J.-L., Calvet, J.-C., Meurey, C., Moigne, P. L., and Trigo, I. F.: Incoming Solar and Infrared Radiation Derived from METEOSAT: Impact on the Modeled Land Water and Energy Budget over France, J. Hydrometeorol., 13, 504-520, https://doi.org/10.1175/JHM-D-11-059.1, 2012.

Castelli, M., Stöckli, R., Zardi, D., Tetzlaff, A., Wagner, J., Belluardo, G., Zebisch, M., and Petitta, M.: The HelioMont method for assessing solar irradiance over complex terrain: Validation and improvements, Remote Sens. Environ., 152, 603-613, https://doi.org/10.1016/j.rse.2014.07.018, 2014.

Cline, D. W.: Snow surface energy exchanges and snowmelt at a continental, midlatitude Alpine site, Water Resour. Res., 33, 689-701, https://doi.org/10.1029/97WR00026, 1997.

Courtier, P., Freydier, C., Geleyn, J.-F., Rabier, F., and Rochas, M.: The ARPEGE project at Météo-France, in: Proceedings of the 1991 ECMWF Seminar, Reading, UK, 193-231, 1991.

Cristóbal, J. and Anderson, M. C.: Validation of a Meteosat Second Generation solar radiation dataset over the northeastern Iberian Peninsula, Hydrol. Earth Syst. Sci., 17, 163-175, https://doi.org/10.5194/hess-17-163-2013, 2013.

DeBeer, C. M. and Pomeroy, J. W.: Influence of snowpack and melt energy heterogeneity on snow cover depletion and snowmelt runoff simulation in a cold mountain environment, J. Hydrol., 553, 199-213, https://doi.org/10.1016/j.jhydrol.2017.07.051, 2017.

Derrien, M. and Le Gléau, H.: MSG/SEVIRI cloud mask and type from SAFNWC, Int. J. Remote Sens., 26, 4707-4732, https://doi.org/10.1080/01431160500166128, 2005.

Derrien, M., Farki, B., Harang, L., Le Gléau, H., Noyalet, A., Pochic, D., and Sairouni, A.: Automatic cloud detection applied to NOAA-11/AVHRR imagery, Remote Sens. Environ., 46, 246267, https://doi.org/10.1016/0034-4257(93)90046-Z, 1993.

Durand, Y., Brun, E., Mérindol, L., Guyomarc'h, G., Lesaffre, B., and Martin, E.: A meteorological estimation of relevant parameters for snow models, Ann. Glaciol., 18, 65-71, https://doi.org/10.1017/S0260305500011277, 1993.

Durand, Y., Giraud, G., Laternser, M., Etchevers, P., Mérindol, L., and Lesaffre, B.: Reanalysis of 47 Years of Climate in the French Alps (1958-2005): Climatology and Trends for Snow Cover, J. Appl. Meteorol. Clim., 48, 2487-2512, https://doi.org/10.1175/2009JAMC1810.1, 2009a.

Durand, Y., Giraud, G., Laternser, M., Etchevers, P., Mérindol, L., and Lesaffre, B.: Reanalysis of $44 \mathrm{Yr}$ of Climate in the French Alps (1958-2002): Methodology, Model Validation, Climatology, and Trends for Air Temperature and Precipitation, J. Appl. Meteorol. Clim., 48, 429-449, https://doi.org/10.1175/2008JAMC1808.1, 2009b.
Fouquart, Y. and Bonnel, B.: Computations of solar heating of the Earth's atmosphere: A new parametrization, Beitr. Phys. Atmosph., 53, 35-62, 1980.

Frouin, R., Lingner, D. W., Gautier, C., Baker, K. S., and Smith, R. C.: A simple analytical formula to compute clear sky total and photosynthetically available solar irradiance at the ocean surface, J. Geophys. Res., 94, 9731-9742, https://doi.org/10.1029/JC094iC07p09731, 1989.

Gautier, C., Diak, G., and Masse, S.: A Simple Physical Model to Estimate Incident Solar Radiation at the Surface from GOES Satellite Data, J. Appl. Meteorol., 19, 1005-1012, https://doi.org/10.1175/15200450(1980)019<1005:ASPMTE>2.0.CO;2, 1980.

Geiger, B., Carrer, D., Franchistéguy, L., Roujean, J. L., and Meurey, C.: Land Surface Albedo Derived on a Daily Basis From Meteosat Second Generation Observations, IEEE T. Geosci. Remote, 46, 3841-3856, https://doi.org/10.1109/TGRS.2008.2001798, 2008a.

Geiger, B., Meurey, C., Lajas, D., Franchistéguy, L., Carrer, D., and Roujean, J.-L.: Near real-time provision of downwelling shortwave radiation estimates derived from satellite observations, Meteorol. Appl., 15, 411-420, https://doi.org/10.1002/met.84, 2008b.

Ghilain, N., Arboleda, A., and Gellens-Meulenberghs, F.: Evapotranspiration modelling at large scale using near-real time MSG SEVIRI derived data, Hydrol. Earth Syst. Sci., 15, 771-786, https://doi.org/10.5194/hess-15-771-2011, 2011.

Günther, D., Marke, T., Essery, R., and Strasser, U.: Uncertainties in Snowpack Simulations-Assessing the Impact of Model Structure, Parameter Choice, and Forcing Data Error on Point-Scale Energy Balance Snow Model Performance, Water Resour. Res., 55, 2779-2800, https://doi.org/10.1029/2018WR023403, 2019.

Hakuba, M. Z., Folini, D., Sanchez-Lorenzo, A., and Wild, M.: Spatial representativeness of ground-based solar radiation measurements, J. Geophys. Res.-Atmos., 118, 8585-8597, https://doi.org/10.1002/jgrd.50673, 2013.

Helbig, N. and Löwe, H.: Shortwave radiation parameterization scheme for subgrid topography, J. Geophys. Res.-Atmos., 117, D03112, https://doi.org/10.1029/2011JD016465, 2012.

Hinkelman, L. M., Lapo, K. E., Cristea, N. C., and Lundquist, J. D.: Using CERES SYN Surface Irradiance Data as Forcing for Snowmelt Simulation in Complex Terrain, J. Hydrometeorol., 16, 2133-2152, https://doi.org/10.1175/JHM-D-14-0179.1, 2015.

Horton, S., Schirmer, M., and Jamieson, B.: Meteorological, elevation, and slope effects on surface hoar formation, The Cryosphere, 9, 1523-1533, https://doi.org/10.5194/tc-9-15232015, 2015.

Ineichen, P., Barroso, C. S., Geiger, B., Hollmann, R., Marsouin, A., and Mueller, R.: Satellite Application Facilities irradiance products: hourly time step comparison and validation over Europe, Int. J. Remote Sens., 30, 5549-5571, https://doi.org/10.1080/01431160802680560, 2009.

Lafaysse, M., Morin, S., Coleou, C., Vernay, M., Serca, D., Besson, F., Willemet, J.-M., Giraud, G., and Durand, Y.: Towards a new chain of models for avalanche hazard forecasting in French mountain ranges, including low altitude mountains, in: Proceedings of International Snow Science Workshop Grenoble-Chamonix Mont-Blanc, 
162-166, available at: http://arc.lib.montana.edu/snow-science/ objects/ISSW13_paper_O1-02.pdf (last access: 20 April 2020), 2013.

Lafaysse, M., Cluzet, B., Dumont, M., Lejeune, Y., Vionnet, V., and Morin, S.: A multiphysical ensemble system of numerical snow modelling, The Cryosphere, 11, 1173-1198, https://doi.org/10.5194/tc-11-1173-2017, 2017.

Lapo, K. E., Hinkelman, L. M., Landry, C. C., Massmann, A. K., and Lundquist, J. D.: A simple algorithm for identifying periods of snow accumulation on a radiometer, Water Resour. Res., 51, 7820-7828, https://doi.org/10.1002/2015WR017590, 2015a.

Lapo, K. E., Hinkelman, L. M., Raleigh, M. S., and Lundquist, J. D.: Impact of errors in the downwelling irradiances on simulations of snow water equivalent, snow surface temperature, and the snow energy balance, Water Resour. Res., 51, 1649-1670, https://doi.org/10.1002/2014WR016259, 2015b.

Lapo, K. E., Hinkelman, L. M., Sumargo, E., Hughes, M., and Lundquist, J. D.: A critical evaluation of modeled solar irradiance over California for hydrologic and land surface modeling, J. Geophys. Res.-Atmos., 122, 299-317, https://doi.org/10.1002/2016JD025527, 2017.

Leroy, M. and Leches, G.: Classification d'un site, Tech. Rep. 35B, Météo-France, available at: http://ccrom.meteo.fr/ccrom/IMG/ pdf/NT035B_V_Nov_2014-3.pdf (last access: 20 April 2020), 2014.

Male, D. H. and Granger, R. J.: Snow surface energy exchange, Water Resour. Res., 17, 609-627, https://doi.org/10.1029/WR017i003p00609, 1981.

Marks, D. and Dozier, J.: Climate and energy exchange at the snow surface in the Alpine Region of the Sierra Nevada: 2. Snow cover energy balance, Water Resour. Res., 28, 3043-3054, https://doi.org/10.1029/92WR01483, 1992.

Marty, C., Philipona, R., Fröhlich, C., and Ohmura, A.: Altitude dependence of surface radiation fluxes and cloud forcing in the Alps: results from the alpine surface radiation budget network, Theor. Appl. Climatol., 72, 137-155, https://doi.org/10.1007/s007040200019, 2002.

Masson, V., Le Moigne, P., Martin, E., Faroux, S., Alias, A., Alkama, R., Belamari, S., Barbu, A., Boone, A., Bouyssel, F., Brousseau, P., Brun, E., Calvet, J.-C., Carrer, D., Decharme, B., Delire, C., Donier, S., Essaouini, K., Gibelin, A.-L., Giordani, H., Habets, F., Jidane, M., Kerdraon, G., Kourzeneva, E., Lafaysse, M., Lafont, S., Lebeaupin Brossier, C., Lemonsu, A., Mahfouf, J.-F., Marguinaud, P., Mokhtari, M., Morin, S., Pigeon, G., Salgado, R., Seity, Y., Taillefer, F., Tanguy, G., Tulet, P., Vincendon, B., Vionnet, V., and Voldoire, A.: The SURFEXv7.2 land and ocean surface platform for coupled or offline simulation of Earth surface variables and fluxes, Geosci. Model Dev., 6, 929-960, https://doi.org/10.5194/gmd-6-929-2013, 2013.

Mlawer, E. J., Taubman, S. J., Brown, P. D., Iacono, M. J., and Clough, S. A.: Radiative transfer for inhomogeneous atmospheres: RRTM, a validated correlated- $k$ model for the longwave, J. Geophys. Res., 102, 16663-16682, https://doi.org/10.1029/97JD00237, 1997.

Moreno, A., Gilabert, M., Camacho, F., and Martínez, B.: Validation of daily global solar irradiation images from MSG over Spain, Renew. Energ., 60, 332-342, https://doi.org/10.1016/j.renene.2013.05.019, 2013.
Morin, S., Lejeune, Y., Lesaffre, B., Panel, J.-M., Poncet, D., David, P., and Sudul, M.: An 18-yr long (1993-2011) snow and meteorological dataset from a mid-altitude mountain site (Col de Porte, France, $1325 \mathrm{~m}$ alt.) for driving and evaluating snowpack models, Earth Syst. Sci. Data, 4, 13-21, https://doi.org/10.5194/essd4-13-2012, 2012.

Müller, M. D. and Scherer, D.: A Grid- and Subgrid-Scale Radiation Parameterization of Topographic Effects for Mesoscale Weather Forecast Models, Mon. Weather Rev., 133, 1431-1442, https://doi.org/10.1175/MWR2927.1, 2005.

Ohmura, A., Gilgen, H., Hegner, H., Müller, G., Wild, M., Dutton, E. G., Forgan, B., Fröhlich, C., Philipona, R., Heimo, A., König-Langlo, G., McArthur, B., Pinker, R., Whitlock, C. H., and Dehne, K.: Baseline Surface Radiation Network (BSRN/WCRP): New Precision Radiometry for Climate Research, B. Am. Meteorol. Soc., 79, 2115-2136, https://doi.org/10.1175/15200477(1998)079<2115:BSRNBW>2.0.CO;2, 1998.

Oliphant, A. J., Spronken-Smith, R. A., Sturman, A. P., and Owens, I. F.: Spatial Variability of Surface Radiation Fluxes in Mountainous Terrain, J. Appl. Meteorol., 42, 113-128, https://doi.org/10.1175/15200450(2003)042<0113:SVOSRF>2.0.CO;2, 2003.

Olson, M., Rupper, S., and Shean, D. E.: Terrain Induced Biases in Clear-Sky Shortwave Radiation Due to Digital Elevation Model Resolution for Glaciers in Complex Terrain, Front. Earth Sci., 7, 216, https://doi.org/10.3389/feart.2019.00216, 2019.

Plüss, C. and Ohmura, A.: Longwave Radiation on SnowCovered Mountainous Surfaces, J. Appl. Meteorol., 36, 818-824, https://doi.org/10.1175/1520-0450-36.6.818, 1997.

Prata, A. J.: A new long-wave formula for estimating downward clear-sky radiation at the surface, Q. J. Roy. Meteorol. Soc., 122, 1127-1151, https://doi.org/10.1002/qj.49712253306, 1996.

Quéno, L., Vionnet, V., Dombrowski-Etchevers, I., Lafaysse, M., Dumont, M., and Karbou, F.: Snowpack modelling in the Pyrenees driven by kilometric-resolution meteorological forecasts, The Cryosphere, 10, 1571-1589, https://doi.org/10.5194/tc-101571-2016, 2016.

Quintana-Seguí, P., Moigne, P. L., Durand, Y., Martin, E., Habets, F., Baillon, M., Canellas, C., Franchisteguy, L., and Morel, S.: Analysis of Near-Surface Atmospheric Variables: Validation of the SAFRAN Analysis over France, J. Appl. Meteorol. Clim., 47, 92-107, https://doi.org/10.1175/2007JAMC1636.1, 2008.

Raleigh, M. S., Lundquist, J. D., and Clark, M. P.: Exploring the impact of forcing error characteristics on physically based snow simulations within a global sensitivity analysis framework, Hydrol. Earth Syst. Sci., 19, 3153-3179, https://doi.org/10.5194/hess-19-3153-2015, 2015.

Ritter, B. and Geleyn, J.-F.: A Comprehensive Radiation Scheme for Numerical Weather Prediction Models with Potential Applications in Climate Simulations, Mon. Weather Rev., 120, 303-325, https://doi.org/10.1175/15200493(1992)120<0303:ACRSFN>2.0.CO;2, 1992.

Rutan, D. A., Kato, S., Doelling, D. R., Rose, F. G., Nguyen, L. T., Caldwell, T. E., and Loeb, N. G.: CERES Synoptic Product: Methodology and Validation of Surface Radiant Flux, J. Atmos. Ocean. Tech., 32, 1121-1143, https://doi.org/10.1175/JTECHD-14-00165.1, 2015. 
Sauter, T. and Obleitner, F.: Assessing the uncertainty of glacier mass-balance simulations in the European Arctic based on variance decomposition, Geosci. Model Dev., 8, 3911-3928, https://doi.org/10.5194/gmd-8-3911-2015, 2015.

Schirmer, M. and Jamieson, B.: Verification of analysed and forecasted winter precipitation in complex terrain, The Cryosphere, 9, 587-601, https://doi.org/10.5194/tc-9-587-2015, 2015.

Schmetz, J., Pili, P., Tjemkes, S., Just, D., Kerkmann, J., Rota, S., and Ratier, A.: An Introduction to Meteosat Second Generation (MSG), B. Am. Meteorol. Soc., 83, 977-992, https://doi.org/10.1175/15200477(2002)083<0977:AITMSG>2.3.CO;2, 2002.

Seity, Y., Brousseau, P., Malardel, S., Hello, G., Bénard, P., Bouttier, F., Lac, C., and Masson, V.: The AROME-France convective scale operational model, Mon. Weather Rev., 129, 976-991, https://doi.org/10.1175/2010MWR3425.1, 2011.

Sicart, J. E., Pomeroy, J. W., Essery, R. L. H., and Bewley, D.: Incoming longwave radiation to melting snow: observations, sensitivity and estimation in Northern environments, Hydrol. Process., 20, 3697-3708, https://doi.org/10.1002/hyp.6383, 2006.

Sicart, J. E., Espinoza, J. C., Quéno, L., and Medina, M.: Radiative properties of clouds over a tropical Bolivian glacier: seasonal variations and relationship with regional atmospheric circulation, Int. J. Climatol., 36, 3116-3128, https://doi.org/10.1002/joc.4540, 2016.

Stöckli, R.: The HelioMont Surface Solar Radiation Processing, Tech. Rep. 93, MeteoSwiss, available at: https://www.meteoswiss.admin.ch/content/dam/meteoswiss/de/ service-und-publikationen/Publikationen/doc/sr93stoeckli.pdf (last access: 20 April 2020), 2013.

Sun, Z., Gebremichael, M., Ardö, J., and de Bruin, H. A. R.: Mapping daily evapotranspiration and dryness index in the East African highlands using MODIS and SEVIRI data, Hydrol. Earth Syst. Sci., 15, 163-170, https://doi.org/10.5194/hess-15163-2011, 2011.
Szczypta, C., Gascoin, S., Houet, T., Hagolle, O., Dejoux, J.-F., Vigneau, C., and Fanise, P.: Impact of climate and land cover changes on snow cover in a small Pyrenean catchment, J. Hydrol., 521, 84-99, https://doi.org/10.1016/j.jhydrol.2014.11.060, 2015.

Trigo, I. F. and Viterbo, P.: Product Requirement Document, Tech. Rep. 1.11, The EUMETSAT Satellite Application Facility on Land Surface Analysis (LSA SAF), available at: https://landsaf.ipma.pt/GetDocument.do?id=281 (last access: 20 April 2020), 2009.

Trigo, I. F., Barroso, C., Viterbo, P., Freitas, S. C., and Monteiro, I. T.: Estimation of downward long-wave radiation at the surface combining remotely sensed data and NWP data, J. Geophys. Res., 115, D24118, https://doi.org/10.1029/2010JD013888, 2010.

Trigo, I. F., Dacamara, C. C., Viterbo, P., Roujean, J.-L., Olesen, F., Barroso, C., de Coca, F. C., Carrer, D., Freitas, S. C., García-Haro, J., Geiger, B., Gellens-Meulenberghs, F., Ghilain, N., Meliá, J., Pessanha, L., Siljamo, N., and Arboleda, A.: The Satellite Application Facility for Land Surface Analysis, Int. J. Remote Sens., 32, 2725-2744, https://doi.org/10.1080/01431161003743199, 2011.

Vionnet, V., Brun, E., Morin, S., Boone, A., Martin, E., Faroux, S., Moigne, P. L., and Willemet, J.-M.: The detailed snowpack scheme Crocus and its implementation in SURFEX v7.2, Geosci. Model. Dev., 5, 773-791, https://doi.org/10.5194/gmd5-773-2012, 2012.

Vionnet, V., Dombrowski-Etchevers, I., Lafaysse, M., Quéno, L., Seity, Y., and Bazile, E.: Numerical weather forecasts at kilometer scale in the French Alps: evaluation and applications for snowpack modelling, J. Hydrometeorol., 17, 2591-2614, https://doi.org/10.1175/JHM-D-15-0241.1, 2016.

WMO: Guide to Meteorological Instruments and Methods of Observation, WMO-No. 8, World Meteorological Organization, Geneva, Switzerland, 2014. 